\title{
ESTUDIO PETROGENETICO DE LAS ROCAS METAMORFICAS DEL MACIZO DE FLORESTA, CORDILLERA ORIENTAL, ANDES COLOMBIANOS
}

\author{
Sandra Rocío Manosalva-Sánchez'; Wilson Enario Naranjo-Merchán ${ }^{1}$; Carlos Alberto Ríos-Reyes²*; \\ Ricardo Amorocho-Parra²; Oscar Mauricio Castellanos-Alarcón ${ }^{3}$
}

DOI: http://dx.doi.org/10.18273/revbol.v39n1-2017004 @ (1)

Forma de citar: Manosalva-Sánchez, S.R., Naranjo-Merchán, W.E., Ríos-Reyes, C.A., Parra, R.A., y Castellanos-Alarcón, O.M. 2017. Estudio petrogenetico de las rocas metamorficas del Macizo de Floresta, Cordillera Oriental, Andes Colombianos. Boletín de Geología, 39(1): 83-103.

\section{RESUMEN}

En la Cordillera Oriental de Colombia se encuentran una serie de antiguos macizos de rocas metamórficas de edad PrecámbricaPaleozoica, los cuales de sur a norte son: Garzón, Quetame, Floresta y Santander, cuyo estudio y entendimiento geológico constituyen parte esencial de la evolución geológica de Colombia. El núcleo del Macizo de Floresta está constituido por rocas metamórficas (Formación Filitas y Esquistos de Busbanzá), de protolito pelítico y semipeliticos de edad pre-Ordovícica, que fueron afectadas por un primer evento de metamorfismo orogénico regional de media P/T (Presión/Temperatura), en donde se desarrollaron filitas, esquistos y paragneis, desde la facies de los esquistos verdes a la facies de la anfibolita. Posterior a este evento en el Ordóvicico (471 $22 \mathrm{Ma}$ ) ocurrió un segundo evento de metamorfismo de contacto, relacionado con una serie de intrusiones graníticas sintectónicas (Stock de Otengá), que desarrolló corneanas, facies hornfelsa piróxeno. Este macizo conforma una estructura anticlinal, con buzamiento hacia el suroccidente y de forma alargada hacia el norte, prolongándose hacia el Macizo de Santander, el cual está limitado lateralmente por los sistemas de Fallas de Boyacá al noroccidente y de Soapaga al suroriente. El núcleo metamórfico e ígneo está muy erodado en la parte central y está cubierto en sus bordes discordantemente por conglomerados, areniscas y lodolitas de edades desde el Devónico hasta el Cretácico Inferior. Los estudios realizados por varios autores siempre relacionan la ocurrencia de cordierita en las unidades de metapelitas; sin embargo, el análisis de química mineral (WDX) mediante microsonda electrónica revela que lo que venía siendo definido como cordieritas corresponde a ortoclasas asociadas con albitas (texturas pertíticas), cambiando así tanto su paragénesis mineral como las condiciones de metamorfismo.

Palabras clave: Metapelitas, Metamorfismo, Filitas y Esquistos de Busbanzá, Macizo de Floresta, Colombia.

\section{PETROGENETIC STUDY OF METAMORPHIC ROCKS OF THE FLORESTA MASSIF, EASTERN CORDILLERA, COLOMBIAN ANDES}

\begin{abstract}
In the Eastern Cordillera of Colombia a series of ancient massifs of metamorphic rocks of Precambrian-Paleozoic age occur, which from south to north are: Garzón, Quetame, Floresta and Santander, whose study and geological understanding constitutes an essential part of the geological evolution of Colombia. The core of the Floresta Massif consists of metamorphic rocks (Busbanzá's Phyllites and Schists Formation) of pelitic and semipelitic protoliths of pre-Ordovician age, which were affected by a first event of regional orogenic metamorphism average P/T (Pressure/Temperature), where phyllites, schists and paraneis were developed, from the greenschist facies to the amphibolite facies and the Ordovician ( $471 \pm 22 \mathrm{Ma})$ for a second event of contact metamorphism, related to a series of granitic intrusions syntectonic (Otengá Stock), which developed hornfels, pyroxene facies hornfelsa. Floresta Massif forms an anticlinal structure, buzante to the southwest and elongated north, extending towards the Massif de Santander, which is limited laterally by the Boyacá and Soapaga fault systems to the northwest and southeast, respectively. The igneous and metamorphic core is highly eroded in the central part and is unconformably covered on its edges by conglomerates, sandstones and mudstones from Devonian to Cretaceous age. Studies by several authors always relate the occurrence of cordierite in the metapelitic units; however, in this study, the analisis of mineral chemistry (WDX) by electron microprobe reveals that what was being defined as cordierite corresponds to orthoclases associated with albites (pertitic textures), thus changing both the mineral assemblages and the conditions of metamorphism.
\end{abstract}

Keywords: Metapelites, metamorphism, Busbanzá Phyllites and Schists, Floresta Massif, Colombia.

\footnotetext{
${ }^{1}$ Escuela de Ingeniería Geológica, Universidad Pedagógica y Tecnológica de Colombia, Sogamoso, Colombia. sandra.manosalva@uptc.edu.co,wilson.naranjo@uptc.edu.co

${ }^{2}$ Escuela de Geología, Universidad Industrial de Santander, Bucaramanga, Colombia. (*) carios@uis.edu.co, amorocho.ricardo@gmail.com

${ }^{3}$ Programa de Geología, Universidad de Pamplona, Pamplona, Colombia. oscarmca@yahoo.es
} 


\section{INTRODUCCIÓN}

Estudios recientes apuntan a la importancia del Macizo de Floresta en la interpretación de la evolución geológica y tectónica de la parte media de la Cordillera Oriental de los Andes Colombianos. Este antiguo macizo expone su basamento ígneo-metamórfico del Precámbrico-Paleozoico a lo largo del flanco este de la Cordillera Oriental, sobre el cual se depositó una cobertera sedimentaria del Paleozoico-Cenozoico. El Macizo de Floresta, gracias a su interés científico y paisajístico, ha sido foco de atención por parte de geocientíficos quienes han estudiado esta región desde diferentes puntos de vista (e.g., Botero, 1950; Cediel, 1969, 1976; Reyes, 1984; Mojica y Villarroel, 1984; Sotelo, 1997; López y Mesa, 1997; Jiménez, 2000; Ulloa et al., 2003; Manosalva et al., 2010).

No obstante, es evidente que existen aún numerosas discrepancias con relación a las rocas metamórficas aflorantes, en particular sobre su litoestratigrafía, rasgos estructurales y ambiente tectónico, los cuales no están aún bien definidos debido a la compleja relación de campo que se presenta como resultado de la sobreimpresión de varios eventos geológicos. De otra parte, en algunos casos su asociación espacial y temporal con las rocas intrusivas de composición principalmente cuarzomonzonítica, aún esta por resolver. Por lo tanto, la literatura existente sobre la geología del Macizo de Floresta refleja la escasez de datos geológicos. El presente trabajo está enfocado al estudio de los rasgos mineralógicos, químicos y texturales de las rocas metamórficas que forman parte del basamento del Macizo de Floresta, así como de sus condiciones de presión y temperatura de metamorfismo, bajo las cuales estas se formaron. Estas rocas revelan una historia geológica que refleja la ocurrencia de un metamorfismo regional de tipo Barroviense de presión baja a intermedia y temperatura baja a alta, aunque sin la definición de un esquema zonal, sobre el cual se ha sobreimpuesto un evento termal (metamorfismo de contacto) asociado al emplazamiento de intrusivos tipo cuarzomonzonita, la cual presenta variaciones a granito y granodiorita. El objetivo del presente estudio es aportar nuevas evidencias petrogenéticas de las rocas metamórficas del Macizo de Floresta, que permitan contribuir en la reconstrucción de su evolución tectono-metamórfica y termal a partir de su estudio petrográfico, historia reaccional, química mineral y geotermobarometría.

\section{MARCO GEOLÓGICO}

El Macizo Floresta de dirección NE-SW está localizado en la Cordillera Oriental de los Andes Colombianos y está delimitado por la Falla Tutasá al oeste y la Falla Soapaga al este (FIGURA 1). Este antiguo macizo representa un excelente escenario para la enseñanza y el aprendizaje de procesos geológicos que se han contribuido al desarrollo del paisaje de la Cordillera Oriental, siendo una de las regiones de mayor interés geocientífico en Colombia. El Macizo de Floresta está delimitado longitudinalmente por las fallas, de Boyacá al noroccidente y la de Soapága al suroriente, ambas con rumbo SW-NE, lo cual condiciona la configuración alargada del macizo en esa dirección. En el Macizo de Floresta afloran rocas cuyas edades oscilan entre el pre-Ordovícico y el Neógeno. El basamento cristalino Paleozoico está constituido por rocas metamórficas del Neis de Buntía y de la Formación Filitas y Esquistos de Busbanzá, las cuales son cortadas por rocas intrusivas de los stocks de Chuscales (granito) y Otengá (cuarzosienita, con variaciones a granito y granodiorita). Ulloa y Rodríguez (1982) reportan una edad $\mathrm{Rb} / \mathrm{Sr}$ de $471 \pm 22 \mathrm{Ma}$ para el Stock de Chuscales que revela su emplazamiento durante el Ordovícico, siendo erodado y cubierto discordantemente por rocas sedimentarias del Devónico. Según Ulloa y Rodríguez (1982), el Stock de Chuscales se diferencia del Stock de Otengá con base en sus diferencias en extensión geográfica, relaciones con las unidades adyacentes y rasgos petrográficos.

Por otra parte, estos autores consideran que este stock presenta xenolitos de conglomerados y limolitas de la Formacion Floresta (Devónico), lo cual se cuestiona en este trabajo en primer lugar porque no hay evidencia de la existencia de conglomerados en la Formación Floresta y en segundo lugar porque la Formación Tibet descansa discordantemente sobre este stock, y, por lo tanto, su edad debería ser pre-Devónica, descartándose su emplazamiento durante el TriásicoJurásico como algunos autores asumen. No obstante, es necesario la determinación de edades radiométricas que permitan dilucidar la edad del Stock de Otengá. El desarrollo de una cuenca extensional producto de la separación de Norteamérica y Suramérica durante el intervalo Triásico-Cretácico temprano, generó en la Cordillera Oriental dos cuencas separadas por un paleoalto del cual el Macizo de Floresta formó 
parte, Cocuy (al oriente) y Tablazo-Magdalena (al occidente), en las cuales se depositó una espesa sucesión de rocas sedimentarias, desde clásticas continentales a marinas, las cuales fueron deformadas durante Paleógeno y principalmente durante el
Neógeno como resultado de la Orogenia Andina (Cooper et al., 1995). Las grandes discordancias presentes en la región delimitan con claridad los principales eventos tectogenéticos.

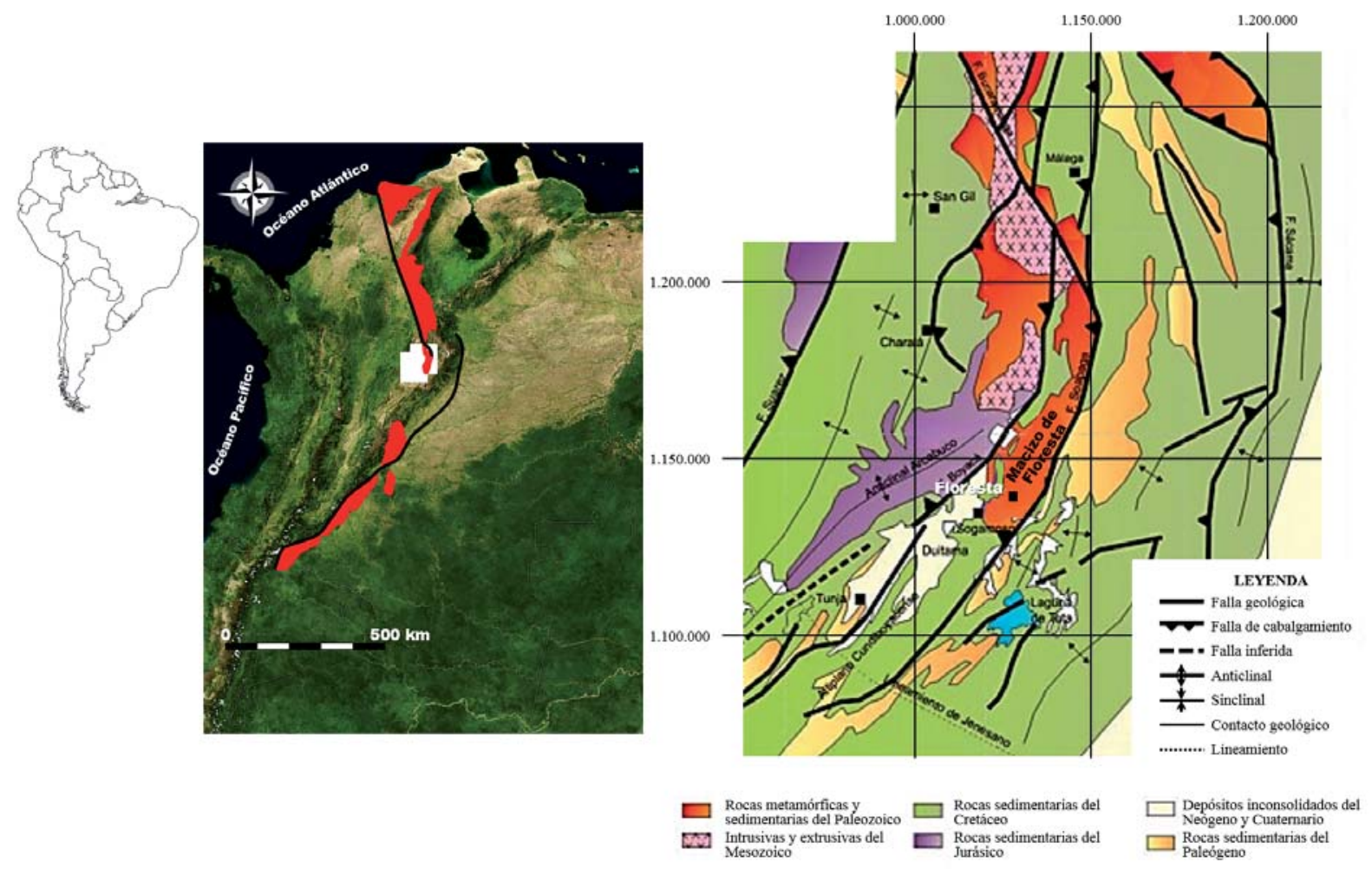

FIGURA 1. Mapa de Localización Macizo de Floresta. La imagen inferior derecha, modelo esquemático, localización de los diferentes tipos de rocas aflorantes en la parte central de la Cordillera Oriental, modificado del Atlas Geológico de Colombia, Ingeominas (1997) y De Freitas et al. (1997) en Velandia (2005).

Las rocas metamórficas en el área han sido estudiadas por varios autores (Botero, 1950; Cediel, 1969, 1976; Mojica y Villarroel, 1984; Sotelo, 1997; Jiménez, 2000; Ulloa et al., 2003; Manosalva et al., 2010), cuyos resultados se sintetizan en la FIGURA 2. Sin embargo, Jiménez (2000) es quien propone oficialmente la denominación de Formación Filitas y Esquistos de Busbanzá, para una secuencia con un espesor aproximado de 890 $\mathrm{m}$, constituida de filitas con intercalaciones menores de metareniscas y cuarcitas, que gradan a esquistos cuarzomicáceos, y cuya localidad tipo se encuentra en la carretera que conduce del Municipio de Busbanzá a Floresta. Adicionalmente Sotelo (1997) y Ulloa et al. (2003) reconocen un ortoneis de composición cuarzo feldespático hornbléndico aflorante a lo largo de la quebrada Buntía dentro del cuerpo intrusivo. Jiménez (2000) dividió la Formación Filitas y Esquistos de
Busbanzá en dos miembros cartografíales, Esquistos de Otengá y Filitas de Ometá, cuya diferenciación se hizo con base en el tamaño de grano, siendo esta unidad de grano más fino hacia la parte oriental (Miembro Filitas de Ometá). Ulloa et al. (2003) diferenciaron tres unidades, el Neis de Buntía (Sotelo, 1997), las Filitas y Esquistos de Busbanzá (Jiménez, 2000) y las Cuarcitas y Filitas de Chuscales. Ulloa et al. (2003) relacionan las secciones levantadas y los análisis petrográficos de Jiménez (2000). La Formación Filitas y Esquistos de Busbanzá es correlacionable con la Formación Silgará, aflorante en la región central del Macizo de Santander, descrita por Ward et al. (1973) y Castellanos et al. (2008), ambas unidades se encuentran intruídas por graníticos Ordovícicos y cubiertas discordantemente por rocas sedimentarias Devónicas. 

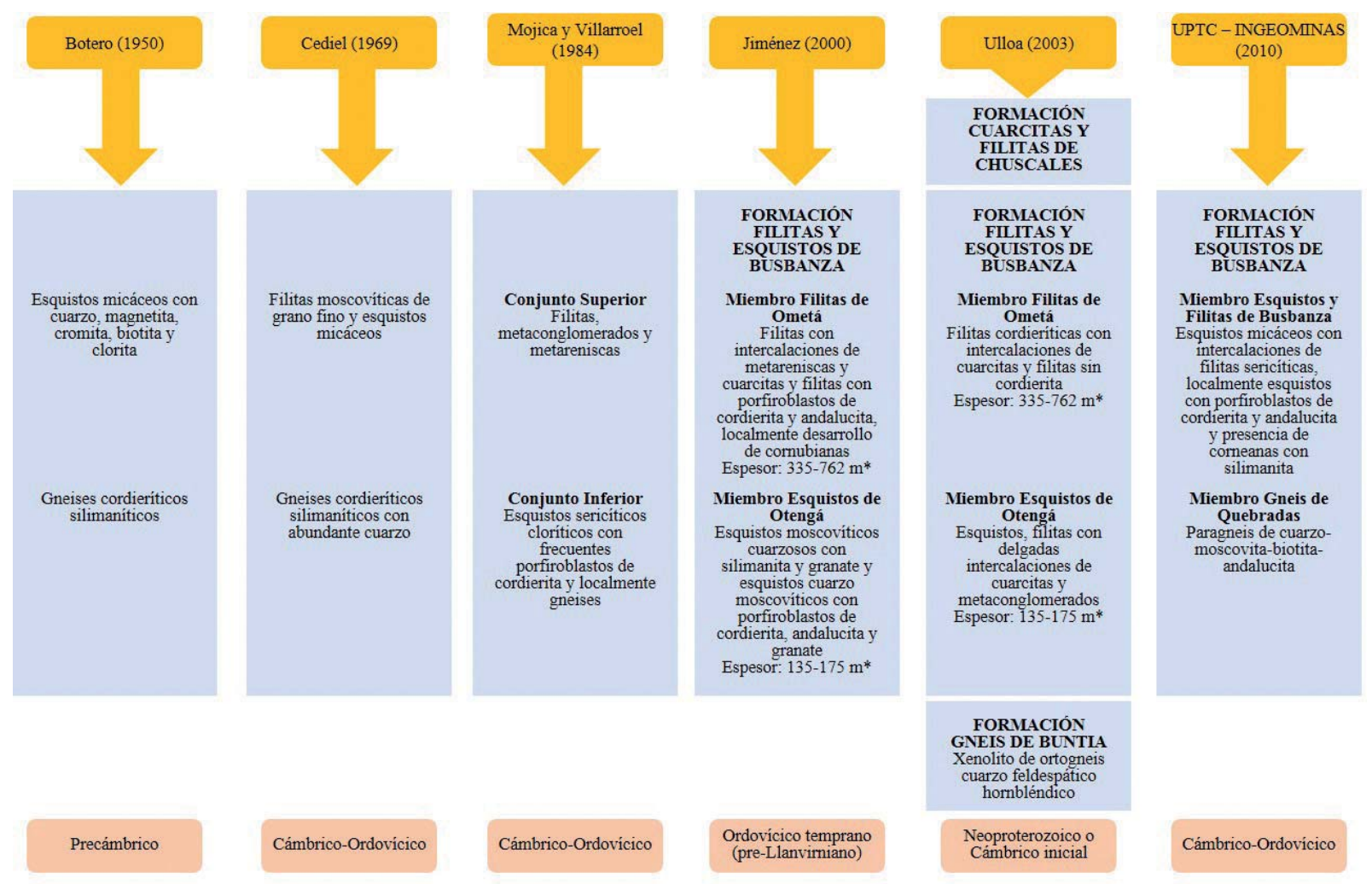

* Medición basada en columna

FIGURA 2. Correlación de las divisiones de las rocas metamórficas propuestas por diferentes autores en el área de estudio.

\section{METODOLOGÍA}

La cartografía geológica de $250 \mathrm{~km}^{2}$ se llevó a cabo a escala 1:10.000 y fue publicada a escala 1:25.000, incluyendo los municipios de Busbanzá, Floresta, Betéitiva, Belén, Cerinza, Tutazá, Santa Rosa de Viterbo y Paz de Río. En las rocas metamórficas se evalúo el metamorfismo a través de las facies y paragénesis mineralógica. En las rocas ígneas se determinó la correlación mineralógica de los cuerpos intrusivos aflorantes, además de la identificación de procesos de cataclasis. Se utilizó la nomenclatura estratigráfica de la Plancha 172-Paz de Río (Ulloa et al., 1998) ajustada con los resultados del presente estudio y las abreviaturas de edades según la International Stratigraphic Chart (Cohen et al., 2013). El análisis petrográfico se llevó a cabo en 23 muestras secciones delgadas utilizando un microscopio petrográfico de investigación OLYMPUS BX51-TRF del laboratorio de Petrografía de la Universidad Pedagógica y Tecnológica de Colombia. La química mineral de 6 muestras de rocas metamórficas se determino por análisis de microsonda electrónica, utilizando un EPMA JEOL-JXA8600, con cinco espectrómetros de dispersión de longitud de onda (WDS) y uno de dispersión de energía (EDS) para análisis cualitativo y cuantitativo, en la Universidad de
Sao Paulo, bajo las siguientes condiciones analíticas: aceleración de voltaje y corriente de prueba de $15 \mathrm{kV}$ y $2.0 \times 10^{-8} \AA$, respectivamente. La adquisición de datos y la reducción se llevaron a cabo usando el método de corrección ZAF, utilizando minerales naturales y sintéticos como estándares. La composición mineral se determinó mediante análisis multipunto. Los cálculos geotermométricos se llevaron a cabo a partir de los pares minerales biotita-moscovita (Hoisch, 1991), plagioclasa-moscovita (Green and Usdansky, 1986), feldespato ternario (e.g., Green and Usdansky, 1986; Fuhrman and Lindsley, 1988), dos feldespatos (e.g., Stormer, 1975; Stormer and Whitney, 1985; Powell and Powell, 1977; Perchuk et al., 1989), y Pl-MsAls-Wt (Cheney and Guidotti, 1979). Los cálculos geobarométricos se realizaron a partir del contenido de Si por fórmula unidad (p.f.u.) en fengita (Massonne and Schreyer, 1987).

\section{RELACIONES DE CAMPO Y PETROGRAFÍA}

Los rasgos geomorfológicos constituyen un componente importante del paisaje de esta región y la base para la integración de sus elementos físicos (FIGURA 3). Con base en criterios, tales como pendiente, tipo de litología, 
vegetación, suelo y morfodinámica, se reconocieron diferentes geoformas, dentro de las que se destacan las unidades (1) de origen denudational, (2) de laderas de acumulación, (3) de alivio agradacional y (4) de origen estructural.

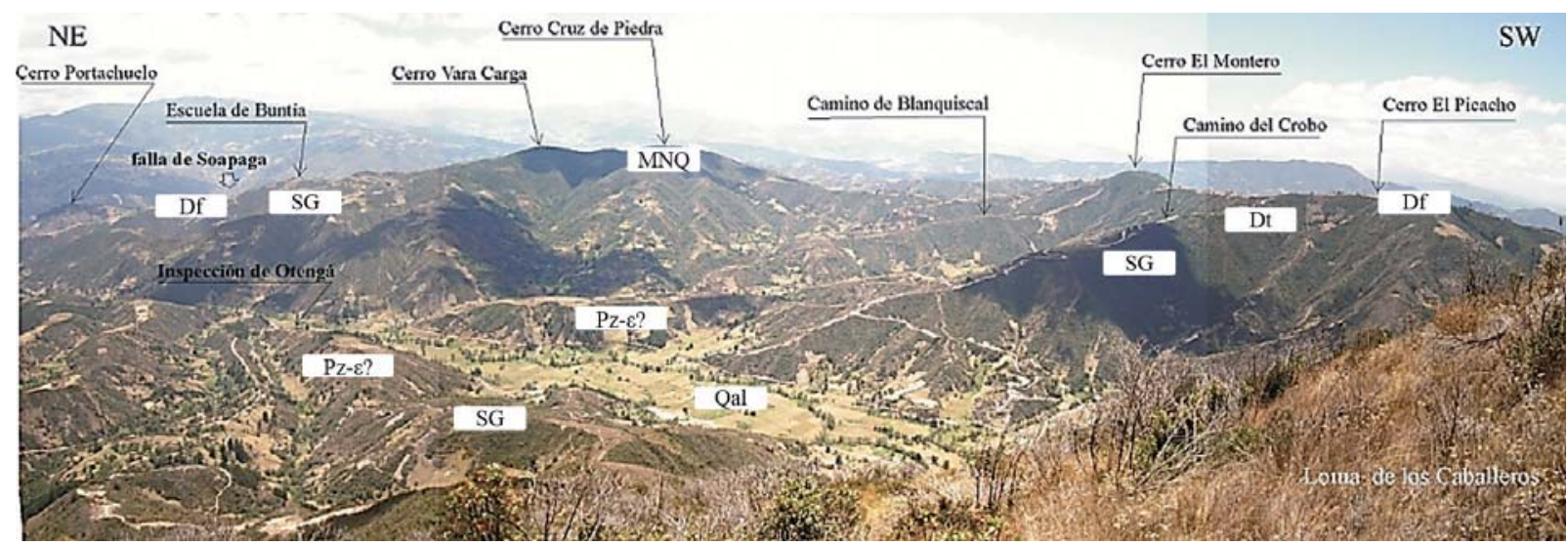

FIGURA 3. Panorámica del área en donde se observa la Formación Filitas y Esquistos de Busbanzá (Pze?) y el Miembro Gneis de Quebradas (MNQ), en contacto intrusivo con los stocks graníticos (SG), sobre los que están discordantemente las Formaciones Tibet (Dt) y Floresta (Df). Nótese la morfología de lomas alargadas peniplanizadas por actividad agrícola en (Qal).

Las rocas metamórficas e ígneas que constituyen el núcleo del Macizo de Floresta están representadas por la Formación Filitas y Esquistos de Busbanzá y el Miembro Gneis de Quebradas del Paleozoico, así como el Stock de Otengá del Ordovícico, los cuales son cubiertos discordantemente por rocas sedimentarias desde el Devónico (formaciones Tíbet y Floresta) hasta el Cretácico (Formación Une), tal como se ilustra en la FIGURA 4. La Formación Filitas y Esquistos de Busbanzá, aflora en la parte oriental del área de estudio, entre Beteitiva y Floresta, extendiéndose en una franja de dirección SW-NE, desde; al oriente y occidente se encuentra en contacto intrusivo con rocas graníticas del Stock de Otengá. Al occidente y norte está en contacto discordante con la Formación Tibet. En el presente estudio, se subdivide la Formación Filitas y Esquistos de Busbanzá, en un miembro inferior, denominado Neis de Quebradas. La división propuesta por Jiménez (2000), miembros Filitas de Ometá y Esquistos de Otengá, no se adopta aquí porque estos no son diferenciables en la sección tipo que aflora a lo largo de la vía que conduce de Floresta a Busbanzá. La Formación Filitas y Esquistos de Busbanzá se encuentra muy replegada, la foliación cambia de dirección e inclinación constantemente, la base de la unidad no es identificable y el techo se encuentra en contacto discordante con la Formación Tibet de edad Devónica, por lo que su espesor real no es posible obtenerse. Jiménez (2000) reporta un espesor de $890 \mathrm{~m}$ mediante cortes geológicos.

El levantamiento estratigráfico de la Formación Filitas y Esquistos de Busbanzá, fue difícil debido al replegamiento, fracturamiento y meteorización que presentan estas rocas. Se levantaron tres secciones litoestratigráficas (FIGURA 5), las cuales se describen brevemente a continuación. La base de la unidad no es identificable y el techo se encuentra en contacto discordante con la Formación Tibet. Estas secciones presentan espesores de 647-1486 m, los cuales presentan repeticiones de la sucesión litológica debido al replegamiento. En algunas secciones es frecuente la presencia de apófisis ígneas, asociada a las cuales se presentó esquistos con porfiroblastos y corneanas de paragénesis biotita + ortoclasa + andalucita, generados por metamorfismo de contacto. En este caso, los porfiroblastos de ortoclasa y andalucita no estan asociados al metamorfismo regional como lo han sugerido otros autores sino que crecieron posttectónicamente como consecuencia de un evento termal asociado al emplazamiento de cuerpos intrusivos. Adicionalmente, producto de la meteorización se presentan suelos cuyas características dependen de la naturaleza de la roca original.

La sección de la vía que conduce de la Escuela Buntía al Cerro Vara Carga se levantó en dirección esteoeste, partiendo del contacto del Stock de Otengá en su franja oriental con el conjunto metamórfico, consiste en una sucesión en donde predominan los esquistos de moscovita, replegados y meteorizados, en la base presenta corneanas de biotita + andalucita con porfiroblastos de hasta $5 \mathrm{~mm}$ de diámetro, y en la parte intermedia apófisis de rocas ígneas graníticas, terminando en el techo con cataclasitas, indicadoras de zona de falla. 

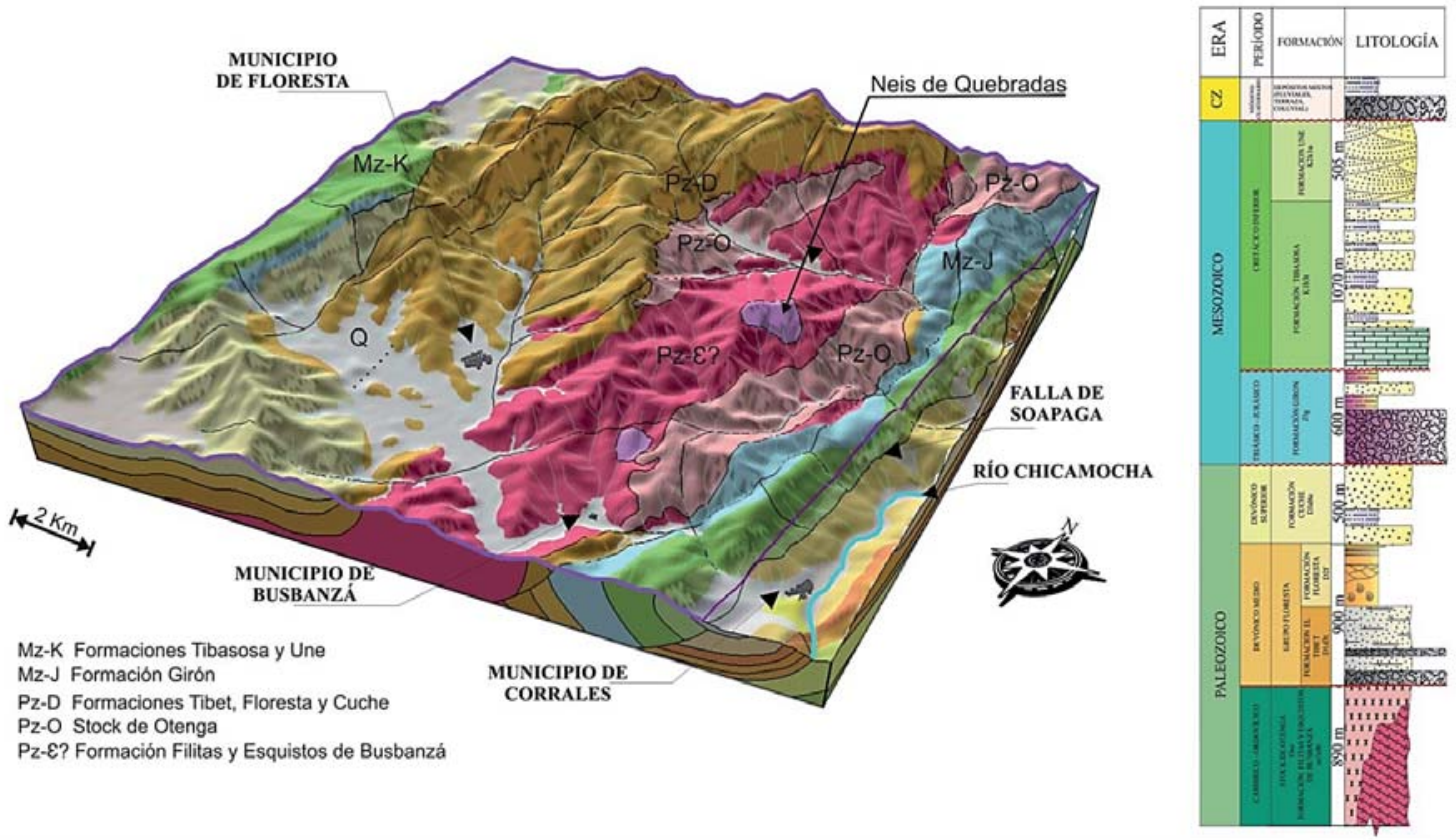

FIGURA 4. Izquierda, mapa geológico 3D ilustrando la distribución de unidades geológicas del Macizo de Floresta. Derecha, columna litoestratigráfica generalizada del Macizo de Floresta.

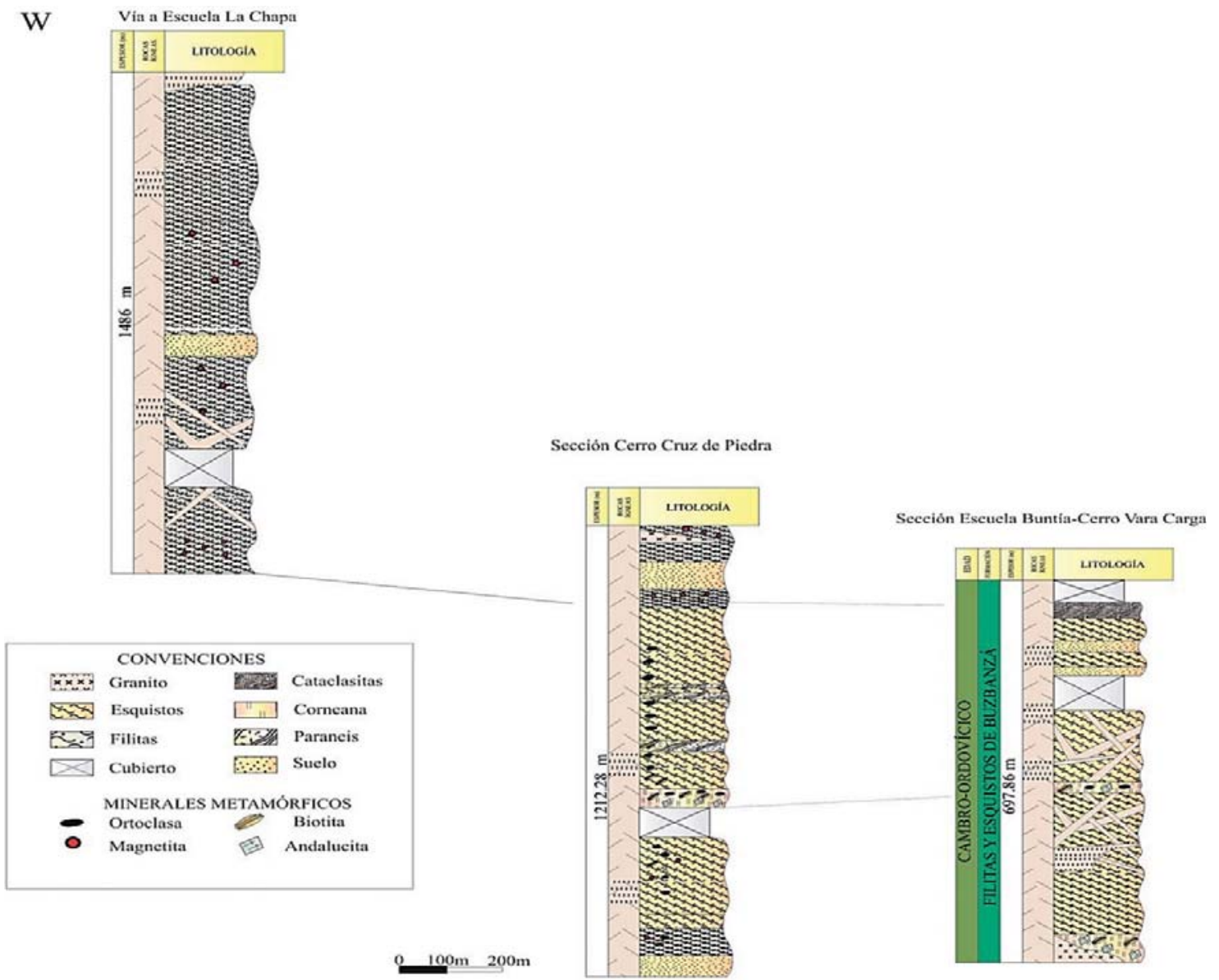

FIGURA 5. Columnas estratigráficas levantadas en la Formación Filitas y Esquistos de Busbanzá. 
La sección de Cerro Cruz de Piedra está compuesta por esquistos y filitas con porfiroblastos de biotita + ortoclasa + andalucita, interestratificados con corneanas y neis en menor proporción. Corresponde con un alto topográfico, en donde la unidad ha sido levantada y rocas formadas a mayor profundidad, como los neis, han sido expuestas. La sección de la vía que conduce a la Escuela La Chapa expone una sucesión monótona compuesta predominantemente por filitas, con laminación planar a ondulada de minerales de magnetita, frecuentemente oxidados a goethita y limonita, localmente con porfiroblastos de ortoclasa.

La Fomación Filitas y Esquistos de Busbanzá esta consituida por rocas metamórficas de afinidad pelítica y semipelítica, con estructura foliada, las cuales sufrieron metamorfismo regional desde la facies de esquistos verdes hasta la facies anfibolita. Estas rocas están representadas por filitas cuarzo-sericíticas, esquistos cuarzomoscovíticos-cloríticos y paraneis con ortoclasa, biotita y andalucita. El emplazamiento a poca profundidad de masas de composición principalmente granítica produjo un efecto térmico sobreimpuesto al metamorfismo regional, lo cual se evidencia en el desarrollo de esquistos con porfiroblastos (mosqueados) y corneanas que muestran texturas de recristalización y formación de nuevos minerales. La FIGURA 6 ilustra las paragénesis minerales típicas de las rocas metamórficas de la Formación Filitas y Esquistos de Busbanzá del Macizo de Floresta.

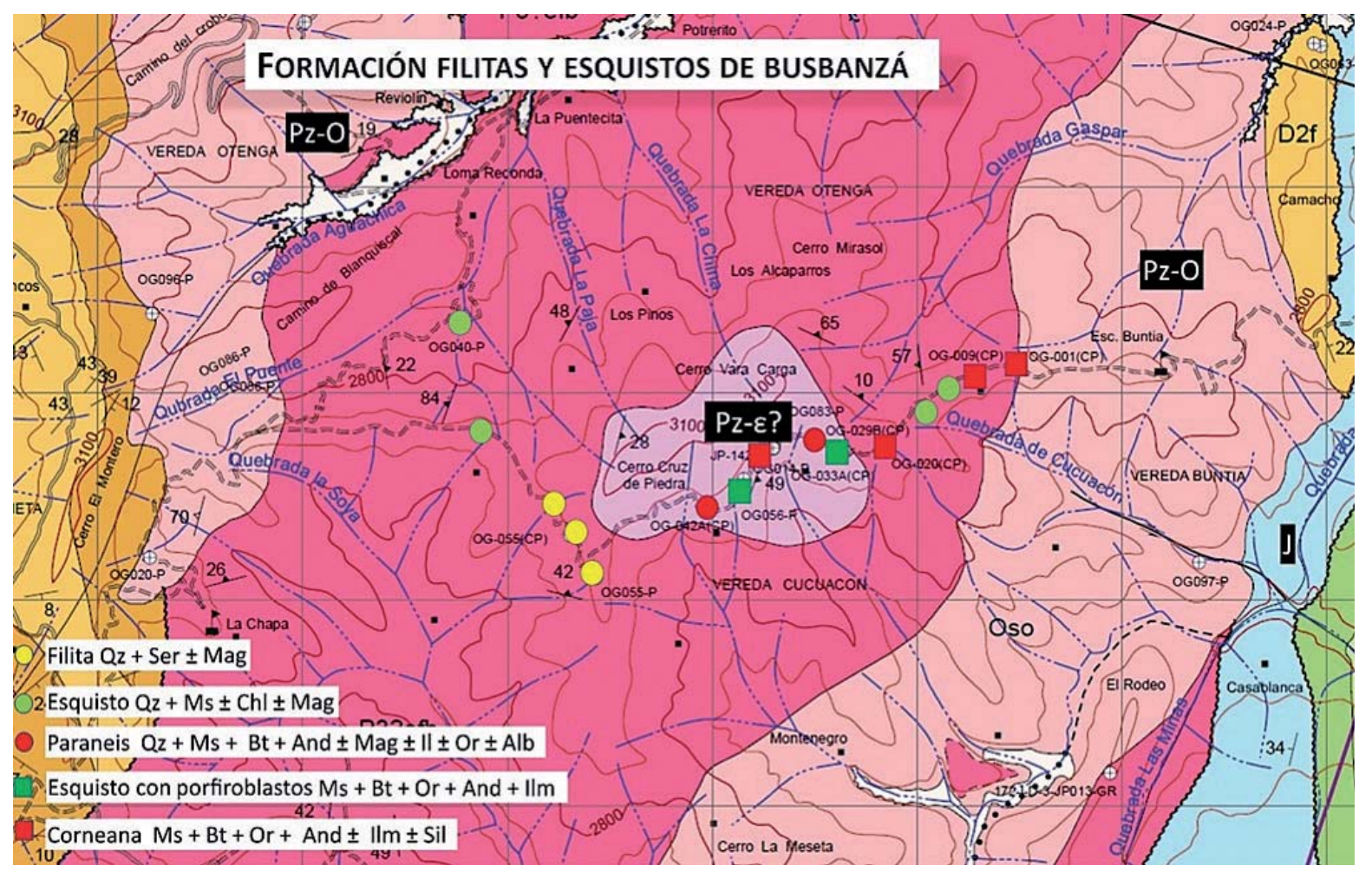

FIGURA 6. Paragénesis mineral de las rocas metamórficas del Macizo de Floresta.

\section{Filitas}

Las mejores exposiciones ocurren en la vereda Horno y Vivas en cercanías a la Escuela San Luis, a lo largo de la vía que conduce de Floresta a Beteitiva, sobre las quebradas Zanjón y El Arenal de la Vereda de Cucuacón, y en el sector "El Pantano" de la Vereda Soiquía. Las filitas se encuentran muy meteorizadas con superficies de alteración de color pardo amarillento debido al contenido de óxidos de hierro (limonita y/o hematita), aunque algunas mejor preservadas presentan tonalidades grisáceas y verdosas. En vía que conduce de Floresta a Busbanzá, el Miembro Filitas de Ometá propuesto por Jiménez (2000) y Ulloa et al. (2003) no fueron identificadas y, por lo tanto, no fueron cartografiables. Las filitas se diferencian de los esquistos por el tamaño de grano muy fino $(0.01-0.1 \mathrm{~mm})$ para las filitas, y de grano fino ó mayores $(0.1 \mathrm{~mm})$ para los esquistos. En muestra de mano el grado de meteorización de las rocas dificultó su reconocimiento, debido a la pérdida de compactación, foliación y brillo sobre los planos de clivaje. Mineralógicamente, las filitas están compuestas por sericita y cuarzo, con magnetita en contenidos menores al $5 \%$ a lo largo de láminas plano paralelas continuas. Texturalmente son granolepidoblásticas y de grano muy fino (FIGURA 7a). 

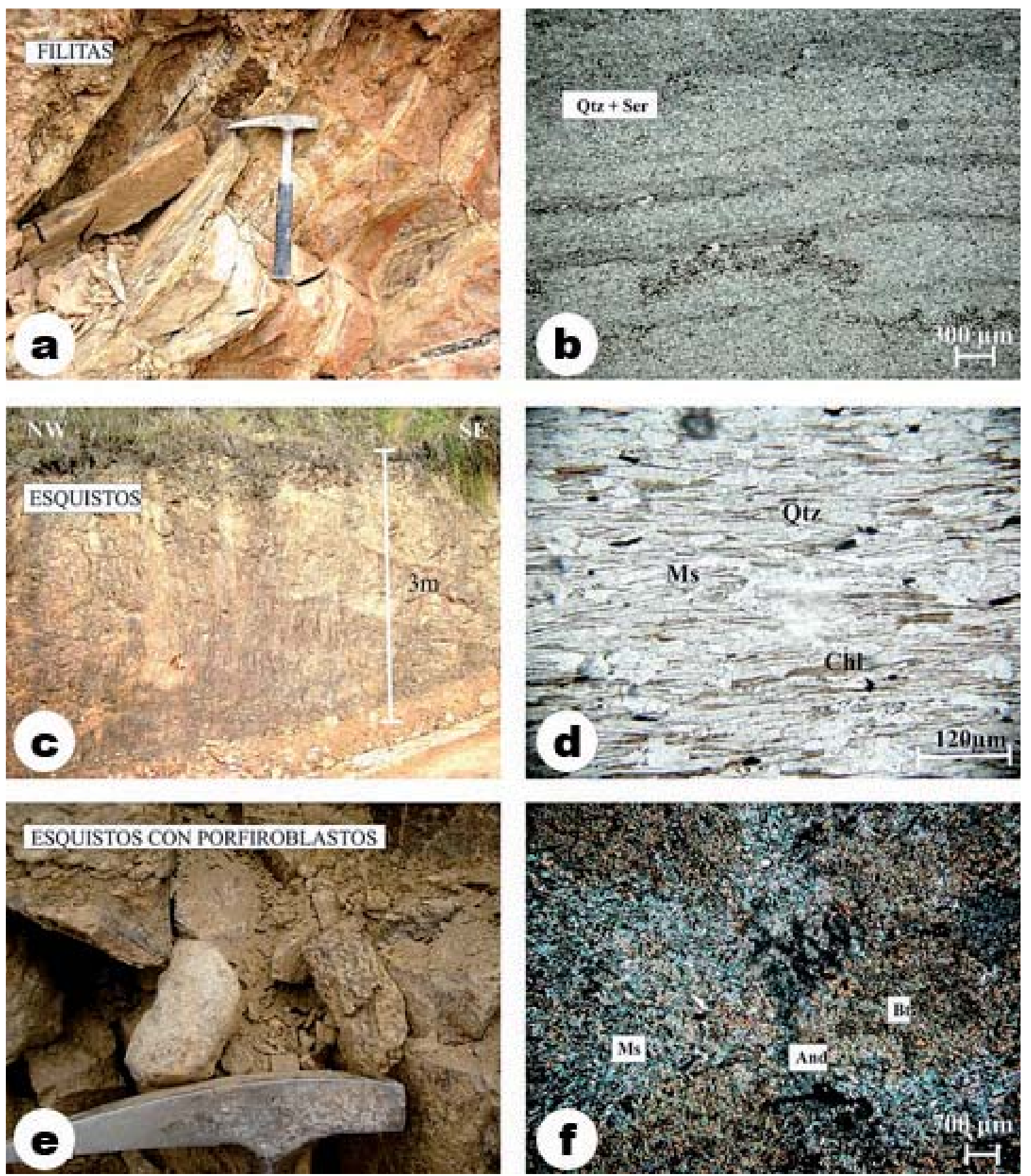

FIGURA 7. (a)-(b) Filitas (1.142.317 N, 1.133.307 E). (c)-(d) Esquisto de moscovita-biotita-cuarzo (1.143.344 N, 1.132.793 E). (e)-(f) Esquistos de moscovita con porfiroblastos (1.142.765 N, 1.134.504 E).

\section{Esquistos Cuarzomicáceos}

Los mejores afloramientos se observan a lo largo de la vía que conduce de Beteitiva al Cerro Montero. Mineralógicamente, están compuestos por cuarzo + moscovita \pm clorita \pm magnetita, con trazas de turmalina y circón. Presentan textura lepidoblástica y, en menor proporción, granolepidoblástica, con tamaño de grano de $0.05-0.25 \mathrm{~mm}$. La moscovita es incolora, aunque comúnmente presenta tonalidades pardas amarillentas debida a la presencia de óxidos de hierro, marcan la esquistosidad de la roca debido a su orientación. Este mineral es de grano muy fino a fino, aunque localmente es de grano grueso con una orientación al azár y exhiben 
cloritización. La moscovita siempre se presenta asociada con cuarzo. La magnetita en algunos casos alcanza hasta un $15 \%$ (FIGURA $7 \mathrm{~b}$ ).

\section{Esquistos con Andalucita}

Estás rocas se caracterizan por la presencia de pórfiroblastos de andalucita, aunque algunos presentan colores negros y verdosos en tamaños de hasta 5 $\mathrm{mm}$ de diámetro. Los porfiroblastos corresponden mineralógicamente a agregados de moscovita + biotita \pm ortoclasa \pm andalucita \pm ilmenita, con desarrollo pseudomorfos después de ortoclasa y andalucita, los cuales son el resultado de fenómenos de rehidratación a finos agregados dominados por sericita (retrogradación). La ortoclasa forma cristales equidimensionales con bordes irregulares y numerosas inclusiones, algunos cristales poseen textura pertitica, con intercrecimientos de albita; son frecuentes las inclusiones de biotita, moscovita y magnetita. Las inclusiones de biotita y moscovita en la ortoclasa, en algunos casos, conservan la orientación de la foliación original de los esquistos, lo cual indica que el crecimiento de la ortoclasa fue post-tectónico, revelando la ocurrencia de un evento térmico sobreimpuesto al desarrollo del metamorfismo regional. Los cristales de andalucita se presentan en porfidoblastos grandes, comúnmente con inclusiones de ortoclasa y biotita (FIGURA 7c).

\section{Gneises}

En la vereda Quebradas y el cerro Cruz de Piedra de la vereda Cucuacón, al noroccidente de Busbanzá se identificaron muy localmente gneises, cuyos afloramientos exhiben coloraciones amarillentas debido a la meteorización. Estas rocas son compactas y presentan fracturamiento, $\mathrm{y}$, en ocasiones, con cortadas por diques de granito. En el presente estudio se propone separar estas rocas de la Formación Filitas y Esquistos de Busbanzá, asignándole la denominación Miembro Gneis de Quebradas, el cual morfológicamente se distingue por presentar altos topográficos (Cerro Cruz de Piedra), donde fue definida la presencia de gneises, los cuales fueron por lo tanto cartografiados. Desde el punto de vista petrográfico, estas rocas presentan una microestructura bandeada, aunque los minerales no muestran orientación, con bandas granoblásticas claras ricas en cuarzo y bandas lepidogranoblásticas oscuras compuestas de moscovita + biotita + andalucita + ortoclasa \pm oligoclasa \pm magnetita \pm ilmenita, con trazas de circón. En la vereda Quebradas, la andalucita está asociada con biotita, mientras que en el Cerro Cruz de Piedra, la ortoclasa se presenta en gneises en bandas oscuras de grano más fino que el Miembro Gneis de Quebradas. Magnetita e ilmenita están presentes hasta en un 10\% (FIGURA 8).
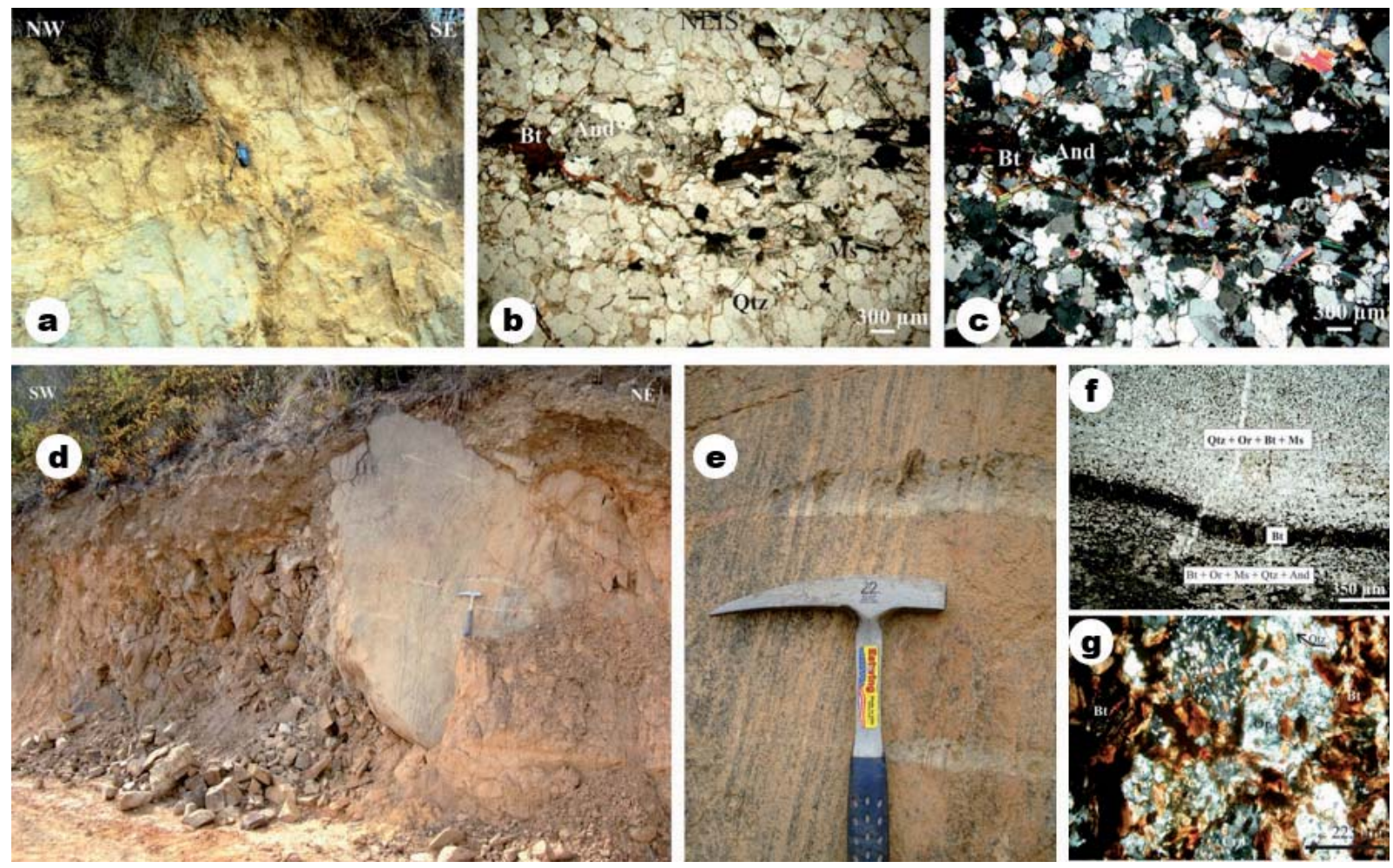

FIGURA 8. (a)-(c) Paraneis (1.138.670 N, 1.132.844 E). (d)-(g) Paraneis (1.142.738 N, 1.134.298 E). 


\section{Corneanas}

Estas rocas aparecen en cercanías al Stock de Otengá y en algunos xenolitos en los Cerros Cruz de Piedra y Vara Carga. Las corneanas son las evidencias de metamorfismo de contacto de alto grado. Mineralógicamente están compuestas por moscovita + biotita + andalucita + ortoclasa \pm ilmenita y biotita + sillimanita + ilmenita \pm cuarzo (FIGURA 9).
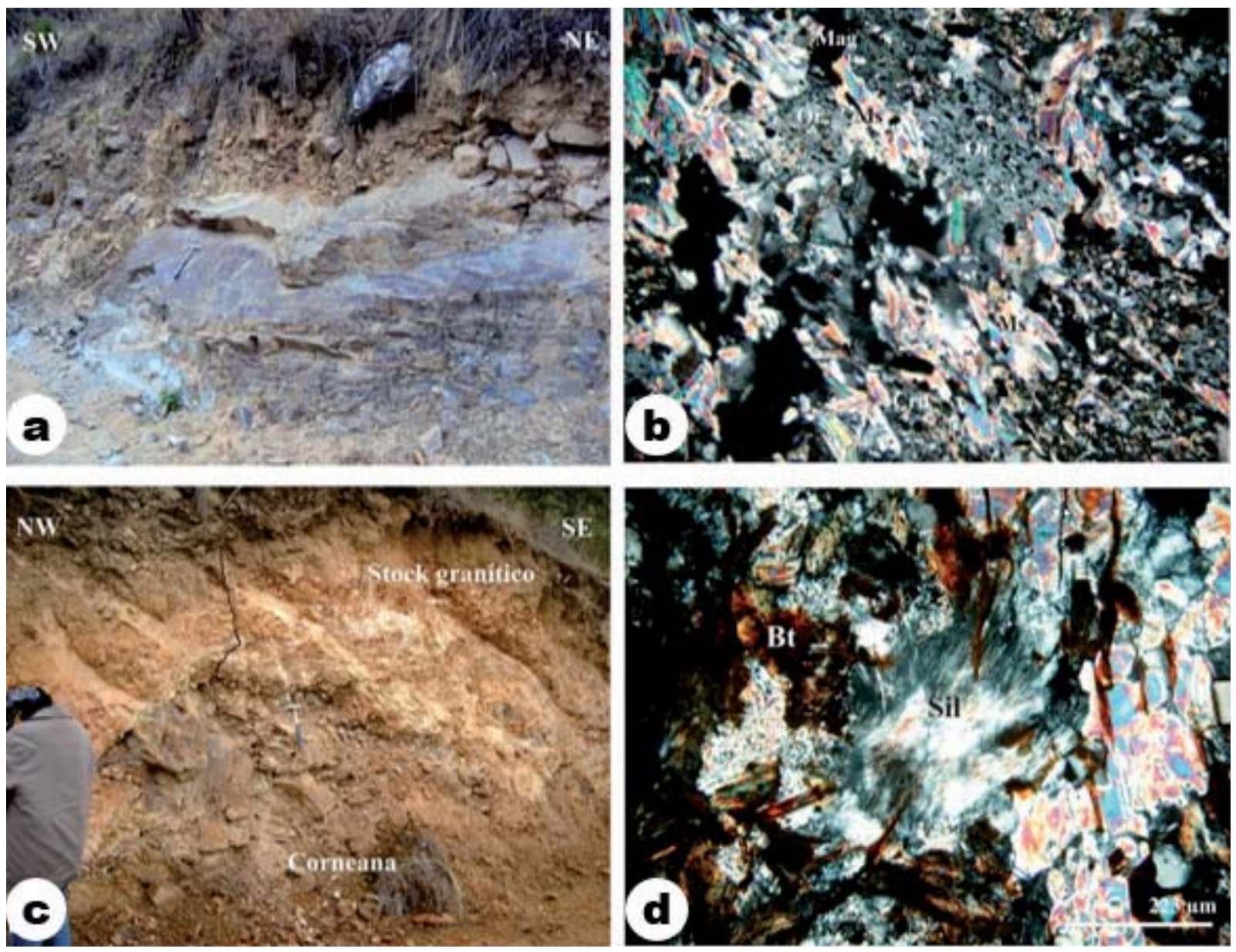

FIGURA 9. (a) Corneana de estructura masiva, roca muy dura (1.142.581 N, 1.134.159 E). (b) Corneana de moscovita (Ms) y ortoclasa (Or). (c) Corneana de sillimanita (1.142.204 N, 1.131.529 E), afloramiento en la vía que de la Escuela la Chapa conduce a Cerro Montero, nótese el xenolito de roca metamórfica. (d) Corneana compuesta por sillimanita (Sil) con hábito fibroso y tabular, menor biotita $(\mathrm{Bt})$.

La FIGURA 10 ilustra los rangos de estabilidad para minerales en condiciones de metamorfismo regional, a partir de lo cual se evidencia que las rocas metamórficas del Macizo de Floresta sufrieron metamorfismo regional de grado bajo a intermedio, con la ausencia de minerales índice como granate, estaurolita y cianita, a pesar de que estudios previos reportan no solo la presencia de granates en esquistos (Jiménez, 2000) sino también de migmatitas (Sotelo, 1997). Sin embargo, esto no se ajusta al metamorfismo regional que se define aquí como base en los rasgos petrográficos observados. Un evento termal asociado al emplazamiento de cuerpos intrusivos se sobreimpuso a este metamorfismo regional con el desarrollo de esquistos con andalucita y corneanas con andalucita + ortoclasa. Estas rocas presentan evidencias de metamorfismo retrógrado como lo desmuestra la ocurrencia de reacciones de rehidratación (alteración de biotita a clorita, plagioclasa y andalucita a sericita y ortoclasa a caolinita), las cuales son o incipientes o llegan a desarrollar pseudomorfos. 


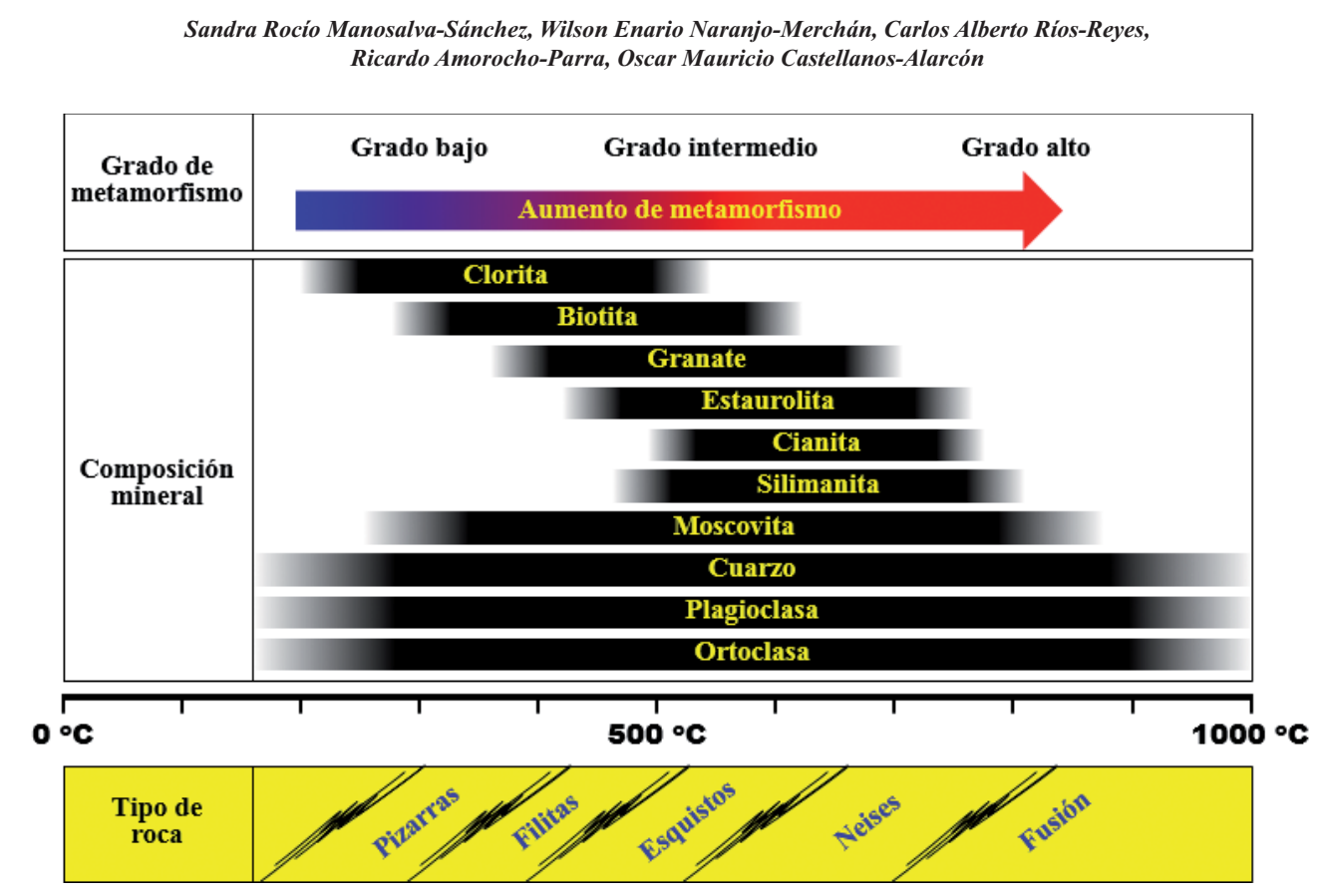

FIGURA 10. Rango de estabilidad mineral con aumento de metamorfismo de rocas pelíticas.

\section{QUÍMICA MINERAL}

A continuación, se describirán las principales características químicas de los minerales analizados: biotita, moscovita, feldespato (plagioclasa y alcalino), andalucita y óxidos (ilmenita y magnetita). Los análisis completos se encuentran en las TABLAS 1-5.

\section{Biotita}

La composición mineral representativa de la biotita se presenta en la TABLA 1 y se ilustra en la FIGURA 11. $\mathrm{Al}^{\mathrm{IV}}$ varía desde 2.650 hasta 2.770 , mientras que $\mathrm{Al}^{\mathrm{VI}}$ varía desde 0.820 hasta 0.960 . El contenido de Ti oscila entre 0.218-0.296. Las sustituciones son importantes en la biotita están representadas por el intercambio $\mathrm{FeMg}_{-1}$ en los sitios octaédricos (annita) y la sustitución Tschermak $\mathrm{Al}_{2} \mathrm{Mg}_{-1} \mathrm{Si}_{-1}$ (eastonita). $\mathrm{La}$ relación $\mathrm{Fe} /(\mathrm{Fe}+\mathrm{Mg})$ de la biotita es de 0.63-0.70.

TABLA 1. Composición mineral representativa de la biotita en la Formación Filitas y Esquistos de Busbanzá.

\begin{tabular}{|c|c|c|c|c|c|c|c|c|c|c|}
\hline \multicolumn{11}{|l|}{ Lithology } \\
\hline Sample No. & OG029CP & OG029CP & OG029CP & OG029CP & G029CP & OG029CP & G033A-P1 & OG033A-P & OG033A-P3 & OG033A-P6 \\
\hline Analysis No. & con Ms & porf. & porf. & porf. & porf. & incl. And & nucleo & & incl. Flds & \\
\hline \multicolumn{11}{|l|}{ Weight \% } \\
\hline $\mathrm{SiO}_{2}$ & 35.06 & 34.92 & 34.86 & 34.10 & 33.99 & 34.22 & 34.47 & 34.90 & 34.75 & 33.58 \\
\hline $\mathrm{TiO}_{2}$ & 1.94 & 2.35 & 2.35 & 2.20 & 2.00 & 2.10 & 1.91 & 2.57 & 2.36 & 2.21 \\
\hline $\mathrm{Al}_{2} \mathrm{O}_{3}$ & 21.04 & 20.71 & 20.62 & 20.28 & 20.21 & 19.53 & 19.64 & 19.68 & 19.69 & 19.22 \\
\hline $\mathrm{FeO}$ & 24.84 & 25.00 & 23.73 & 23.41 & 23.14 & 24.99 & 22.92 & 21.84 & 22.24 & 21.26 \\
\hline MnO & 0.14 & 0.07 & 0.07 & 0.12 & 0.09 & 0.09 & 0.24 & 0.21 & 0.24 & 0.22 \\
\hline MgO & 6.52 & 6.30 & 6.26 & 6.39 & 6.37 & 6.12 & 7.48 & 6.94 & 6.99 & 6.93 \\
\hline $\mathrm{ZnO}$ & 0.04 & 0.03 & 0.03 & 0.00 & 0.01 & 0.08 & 0.07 & 0.01 & 0.02 & 0.00 \\
\hline $\mathrm{CaO}$ & 0.00 & 0.02 & 0.02 & 0.00 & 0.03 & 0.01 & 0.00 & 0.02 & 0.03 & 0.05 \\
\hline $\mathrm{BaO}$ & 0.02 & 0.07 & 0.07 & 0.08 & 0.04 & 0.08 & 0.10 & 0.05 & 0.10 & 0.03 \\
\hline $\mathrm{Na}_{2} \mathrm{O}$ & 0.05 & 0.17 & 0.17 & 0.15 & 0.14 & 0.14 & 0.18 & 0.12 & 0.09 & 0.09 \\
\hline $\mathrm{K}_{2} \mathrm{O}$ & 9.93 & 9.88 & 9.88 & 9.85 & 9.68 & 9.96 & 9.80 & 9.68 & 9.76 & 9.78 \\
\hline
\end{tabular}




\begin{tabular}{|c|c|c|c|c|c|c|c|c|c|c|}
\hline \multicolumn{11}{|l|}{ Lithology } \\
\hline Sample No. & OG029CP & OG029CP & OG029CP & OG029CP & OG029CP & OG029CP & OG033A-P1 & OG033A-P2 & OG033A-P3 & OG033A-P6 \\
\hline Analysis No. & con $\mathrm{Ms}$ & porf. & porf. & porf. & porf. & incl. And & nucleo & & incl. Flds & \\
\hline \multicolumn{11}{|l|}{ Weight \% } \\
\hline Cl & 0.01 & 0.00 & 0.00 & 0.01 & 0.00 & 0.03 & 0.02 & 0.01 & 0.01 & 0.02 \\
\hline $\mathbf{F}$ & 0.05 & 0.10 & 0.10 & 0.11 & 0.01 & 0.45 & 0.01 & 0.06 & 0.00 & 0.15 \\
\hline $\mathrm{O}=(\mathrm{F}, \mathrm{Cl})$ & 0.03 & 0.05 & 0.05 & 0.05 & 0.01 & 0.21 & 0.02 & 0.03 & 0.00 & 0.06 \\
\hline Total & 99.31 & 99.10 & 97.64 & 96.19 & 95.39 & 96.71 & 96.19 & 95.57 & 95.78 & 92.91 \\
\hline \multicolumn{11}{|c|}{ Cation Numbers (based on 22 O) } \\
\hline $\mathbf{S i}$ & 5.238 & 5.231 & 5.272 & 5.245 & 5.266 & 5.272 & 5.282 & 5.348 & 5.329 & 5.309 \\
\hline $\mathbf{T i}$ & 0.218 & 0.265 & 0.268 & 0.255 & 0.233 & 0.244 & 0.220 & 0.296 & 0.272 & 0.263 \\
\hline Al & 3.705 & 3.656 & 3.676 & 3.677 & 3.690 & 3.546 & 3.547 & 3.554 & 3.559 & 3.582 \\
\hline $\mathrm{Fe}$ & 3.103 & 3.132 & 3.001 & 3.011 & 2.998 & 3.219 & 2.937 & 2.799 & 2.852 & 2.811 \\
\hline Mn & 0.017 & 0.009 & 0.009 & 0.015 & 0.011 & 0.011 & 0.031 & 0.027 & 0.031 & 0.030 \\
\hline $\mathrm{Mg}$ & 1.452 & 1.406 & 1.410 & 1.464 & 1.471 & 1.405 & 1.707 & 1.585 & 1.596 & 1.633 \\
\hline $\mathbf{Z n}$ & 0.004 & 0.003 & 0.003 & 0.000 & 0.001 & 0.009 & 0.008 & 0.001 & 0.002 & 0.000 \\
\hline $\mathrm{Ca}$ & 0.001 & 0.003 & 0.003 & 0.000 & 0.005 & 0.001 & 0.000 & 0.003 & 0.004 & 0.008 \\
\hline Ba & 0.001 & 0.004 & 0.004 & 0.005 & 0.002 & 0.005 & 0.006 & 0.003 & 0.006 & 0.002 \\
\hline $\mathrm{Na}$ & 0.014 & 0.050 & 0.050 & 0.045 & 0.043 & 0.042 & 0.054 & 0.035 & 0.025 & 0.029 \\
\hline $\mathbf{K}$ & 1.893 & 1.887 & 1.906 & 1.933 & 1.914 & 1.958 & 1.917 & 1.892 & 1.909 & 1.972 \\
\hline Suma cat. & 15.645 & 15.645 & 15.601 & 15.651 & 15.635 & 15.711 & 15.710 & 15.543 & 15.587 & 15.638 \\
\hline \multicolumn{11}{|l|}{ Anions } \\
\hline Cl & 0.003 & 0.000 & 0.000 & 0.002 & 0.000 & 0.008 & 0.006 & 0.002 & 0.003 & 0.005 \\
\hline F & 0.026 & 0.048 & 0.049 & 0.053 & 0.003 & 0.221 & 0.006 & 0.028 & 0.000 & 0.075 \\
\hline $\mathrm{Al}^{\mathrm{IV}}$ & 2.760 & 2.770 & 2.730 & 2.750 & 2.730 & 2.730 & 2.720 & 2.650 & 2.670 & 2.690 \\
\hline $\mathbf{A l}^{\mathrm{VI}}$ & 0.940 & 0.890 & 0.950 & 0.920 & 0.960 & 0.820 & 0.830 & 0.900 & 0.890 & 0.890 \\
\hline $\mathrm{Fe} /(\mathrm{Fe}+\mathrm{Mg})$ & 0.68 & 0.69 & 0.68 & 0.67 & 0.67 & 0.70 & 0.63 & 0.64 & 0.64 & 0.63 \\
\hline
\end{tabular}

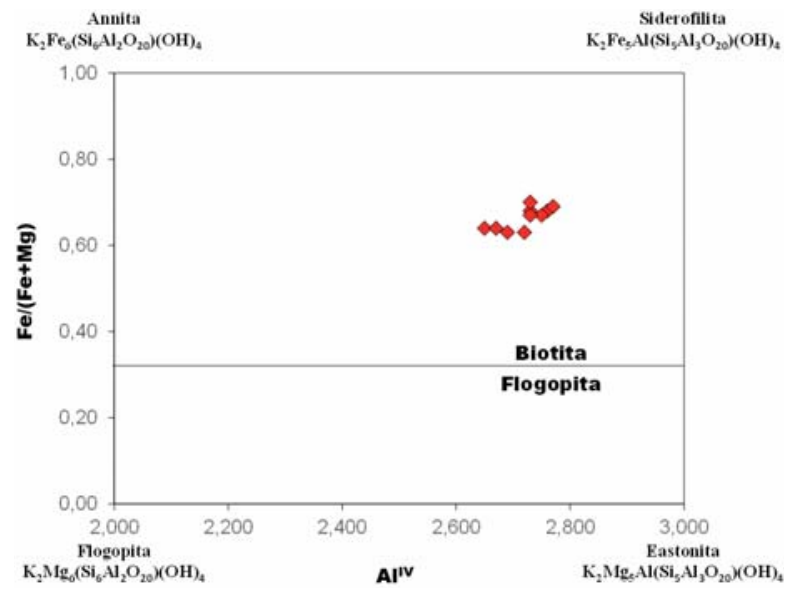

FIGURA 11. Composición química de la biotita en la paragénesis moscovita + biotita + feldespato alcalino + cuarzo + $\mathrm{H}_{2} \mathrm{O}$ de la Formación Filitas y Esquistos de Busbanzá expresada en parte del cuadrilátero flogopita-annita-eastonita-siderofilita.

\section{Moscovita}

La composición mineral representativa de la moscovita se presenta en la TABLA 2. El contenido de Si varía de 6.051-6.475. El contenido de celadonita, ( $\mathrm{Si} / 2)-3$, varía de 0.03-0.24, y la relación $\mathrm{Na} /(\mathrm{Na}+\mathrm{K})$ ratio varies from 0.01-0.08 (FIGURA 12). Según Ríos et al. (2003), la fracción molar de paragonito disminuye con el aumento de celadonita y aumenta con el aumento del grado de metamorfismo para un contenido de celadonita fijo. La moscovita presenta una composición química cercana a la del miembro extremo moscovita, la cual a baja temperatura se experaría que tienda hacia a del miembro extremo celadonita. 
Sandra Rocío Manosalva-Sánchez, Wilson Enario Naranjo-Merchán, Carlos Alberto Ríos-Reyes, Ricardo Amorocho-Parra, Oscar Mauricio Castellanos-Alarcón

TABLA 2. Composición mineral representativa de la moscovita en la Formación Filitas y Esquistos de Busbanzá.

\begin{tabular}{|c|c|c|c|c|c|c|c|c|c|c|c|}
\hline \multicolumn{12}{|l|}{ Lithology } \\
\hline Sample No. & OG029CP & OG029CP & OG029CP & OG033A-P3 & OG033A-P6 & JP203P & JP203P & JP203P & OG056P-P2 & OG040P & JP278-P4 \\
\hline Analysis No. & porf. & orient. & orient. & incl. Flds. & cerca a Op & nucleo & incl. Zrn & alter. And & cerca a Op & & nucleo \\
\hline \multicolumn{12}{|l|}{ Weight \% } \\
\hline $\mathrm{SiO}_{2}$ & 45.34 & 45.67 & 46.38 & 45.63 & 45.89 & 45.50 & 44.76 & 49.28 & 46.69 & 45.25 & 45.45 \\
\hline $\mathrm{TiO}_{2}$ & 0.47 & 0.73 & 0.64 & 0.67 & 0.78 & 1.10 & 0.82 & 0.06 & 0.40 & 0.78 & 0.45 \\
\hline $\mathrm{Al}_{2} \mathrm{O}_{3}$ & 35.71 & 35.71 & 36.49 & 35.07 & 35.07 & 33.56 & 34.06 & 31.57 & 33.61 & 32.37 & 29.32 \\
\hline $\mathrm{Fe}_{2} \mathrm{O}_{3}$ & 1.13 & 1.20 & 1.32 & 2.31 & 2.23 & 3.01 & 3.02 & 3.53 & 2.83 & 2.79 & 6.98 \\
\hline MnO & 0.00 & 0.01 & 0.00 & 0.00 & 0.00 & 0.00 & 0.02 & 0.04 & 0.00 & 0.02 & 0.09 \\
\hline MgO & 0.37 & 0.45 & 0.41 & 0.48 & 0.57 & 0.68 & 0.61 & 1.55 & 1.36 & 0.72 & 2.09 \\
\hline $\mathrm{ZnO}$ & 0.01 & 0.01 & 0.03 & 0.00 & 0.00 & 0.01 & 0.00 & 0.03 & 0.02 & 0.07 & 0.02 \\
\hline $\mathrm{CaO}$ & 0.01 & 0.00 & 0.00 & 0.00 & 0.02 & 0.00 & 0.02 & 0.26 & 0.03 & 0.01 & 0.05 \\
\hline $\mathrm{BaO}$ & 0.05 & 0.00 & 0.02 & 0.04 & 0.00 & 0.05 & 0.04 & 0.05 & 0.14 & 0.09 & 0.00 \\
\hline $\mathrm{Na}_{2} \mathrm{O}$ & 0.53 & 0.46 & 0.50 & 0.50 & 0.46 & 0.41 & 0.45 & 0.08 & 0.30 & 0.62 & 0.14 \\
\hline $\mathrm{K}_{2} \mathrm{O}$ & 11.27 & 10.52 & 11.26 & 11.14 & 10.34 & 11.15 & 10.91 & 9.76 & 11.07 & 10.66 & 11.02 \\
\hline $\mathrm{Cl}$ & 0.01 & 0.00 & 0.02 & 0.00 & 0.01 & 0.00 & 0.00 & 0.01 & 0.00 & 0.00 & 0.00 \\
\hline F & 0.00 & 0.00 & 0.12 & 0.00 & 0.29 & 0.00 & 0.12 & 0.30 & 0.29 & 0.00 & 0.17 \\
\hline $\mathrm{O}=(\mathrm{F}, \mathrm{Cl})$ & 0.00 & 0.00 & 0.05 & 0.00 & 0.12 & 0.00 & 0.05 & 0.13 & 0.12 & 0.00 & 0.07 \\
\hline Total & 94.88 & 94.75 & 97.13 & 95.83 & 95.51 & 95.46 & 94.78 & 96.40 & 96.60 & 93.36 & 95.72 \\
\hline \multicolumn{12}{|c|}{ Cation Numbers (based on 22 O) } \\
\hline $\mathbf{S i}$ & 6.079 & 6.098 & 6.072 & 6.077 & 6.105 & 6.106 & 6.051 & 6.475 & 6.185 & 6.197 & 6.183 \\
\hline $\mathbf{T i}$ & 0.047 & 0.073 & 0.063 & 0.067 & 0.078 & 0.111 & 0.083 & 0.006 & 0.040 & 0.080 & 0.046 \\
\hline Al & 5.644 & 5.620 & 5.631 & 5.505 & 5.499 & 5.308 & 5.427 & 4.890 & 5.248 & 5.226 & 4.701 \\
\hline $\mathrm{Fe}^{3+}$ & 0.114 & 0.121 & 0.130 & 0.231 & 0.223 & 0.304 & 0.307 & 0.349 & 0.282 & 0.288 & 0.714 \\
\hline Mn & 0.000 & 0.001 & 0.000 & 0.000 & 0.000 & 0.000 & 0.003 & 0.004 & 0.000 & 0.002 & 0.011 \\
\hline Mg & 0.074 & 0.089 & 0.080 & 0.094 & 0.112 & 0.136 & 0.124 & 0.304 & 0.269 & 0.147 & 0.424 \\
\hline $\mathbf{Z n}$ & 0.001 & 0.001 & 0.003 & 0.000 & 0.000 & 0.000 & 0.000 & 0.003 & 0.001 & 0.007 & 0.002 \\
\hline $\mathrm{Ca}$ & 0.001 & 0.000 & 0.000 & 0.000 & 0.003 & 0.000 & 0.002 & 0.037 & 0.004 & 0.001 & 0.007 \\
\hline Ba & 0.003 & 0.000 & 0.001 & 0.002 & 0.000 & 0.002 & 0.002 & 0.002 & 0.007 & 0.005 & 0.000 \\
\hline $\mathrm{Na}$ & 0.138 & 0.119 & 0.126 & 0.129 & 0.118 & 0.107 & 0.118 & 0.021 & 0.077 & 0.163 & 0.037 \\
\hline K & 1.927 & 1.792 & 1.881 & 1.892 & 1.754 & 1.909 & 1.882 & 1.636 & 1.870 & 1.862 & 1.912 \\
\hline Suma cat. & 14.027 & 13.914 & 13.988 & 13.998 & 13.892 & 13.985 & 13.998 & 13.728 & 13.983 & 13.978 & 14.038 \\
\hline \multicolumn{12}{|l|}{ Anions } \\
\hline $\mathrm{Cl}$ & 0.003 & 0.000 & 0.004 & 0.001 & 0.002 & 0.001 & 0.000 & 0.002 & 0.001 & 0.000 & 0.000 \\
\hline $\mathbf{F}$ & 0.000 & 0.002 & 0.049 & 0.000 & 0.123 & 0.000 & 0.052 & 0.125 & 0.120 & 0.000 & 0.073 \\
\hline$\overline{\mathrm{Al}^{\mathrm{IV}}}$ & 1.92 & 1.90 & 1.93 & 1.92 & 1.89 & 1.89 & 1.95 & 1.52 & 1.81 & 1.80 & 1.82 \\
\hline $\mathbf{A l}^{\mathrm{VI}}$ & 3.72 & 3.72 & 3.70 & 3.58 & 3.60 & 3.41 & 3.48 & 3.37 & 3.43 & 3.42 & 2.88 \\
\hline $\mathrm{Fe} /(\mathbf{F e}+\mathbf{M g})$ & 0.61 & 0.57 & 0.62 & 0.71 & 0.67 & 0.69 & 0.71 & 0.53 & 0.51 & 0.66 & 0.68 \\
\hline $\mathbf{S i}$ & 6.079 & 6.098 & 6.072 & 6.077 & 6.105 & 6.106 & 6.051 & 6.475 & 6.185 & 6.197 & 6.183 \\
\hline$(\mathrm{Si} / 2)-3$ & 0.04 & 0.05 & 0.04 & 0.04 & 0.05 & 0.05 & 0.03 & 0.24 & 0.09 & 0.10 & 0.09 \\
\hline $\mathrm{Na} /(\mathrm{Na}+\mathrm{K})$ & 0.07 & 0.06 & 0.06 & 0.06 & 0.06 & 0.05 & 0.06 & 0.01 & 0.04 & 0.08 & 0.02 \\
\hline
\end{tabular}




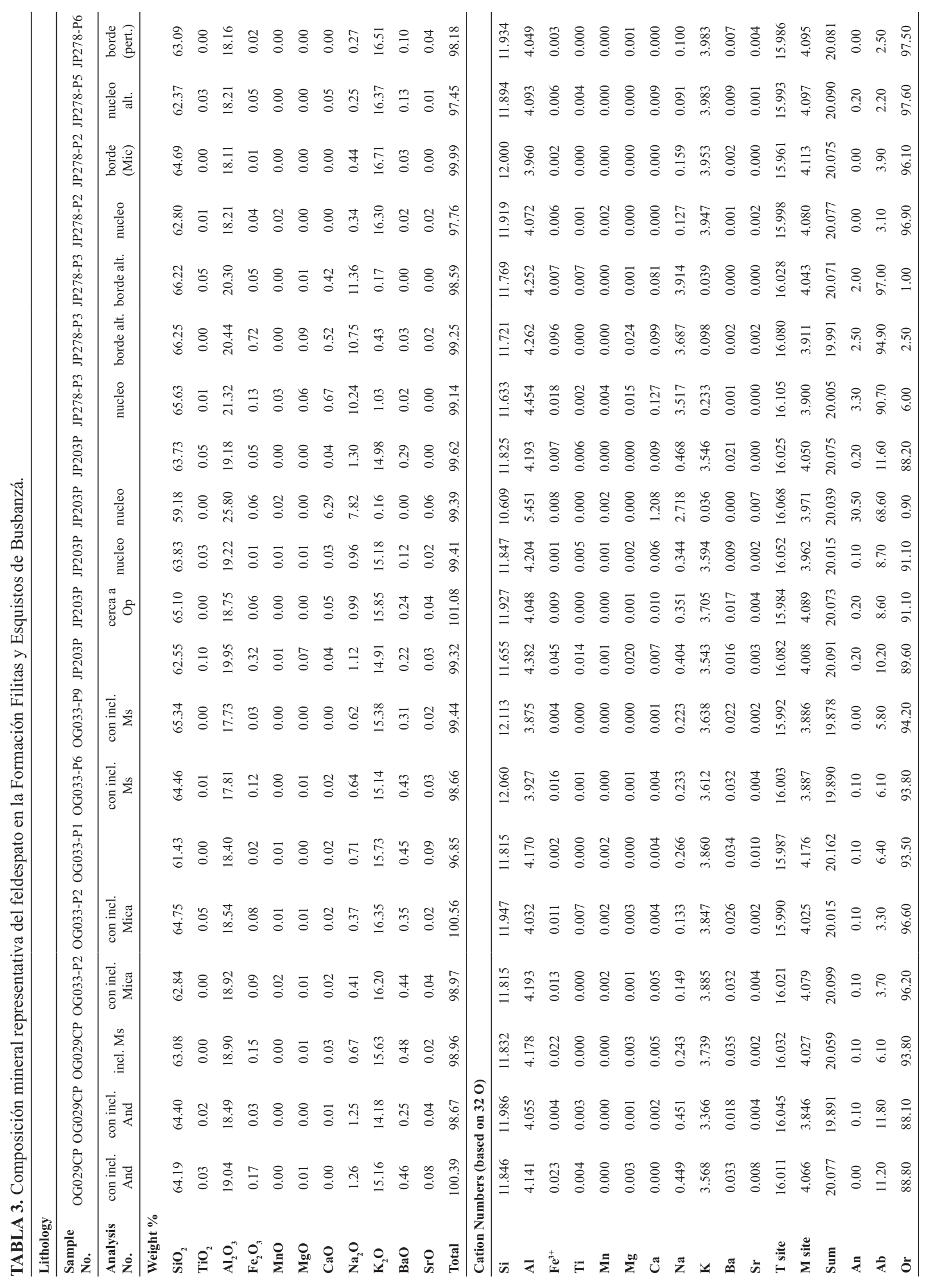




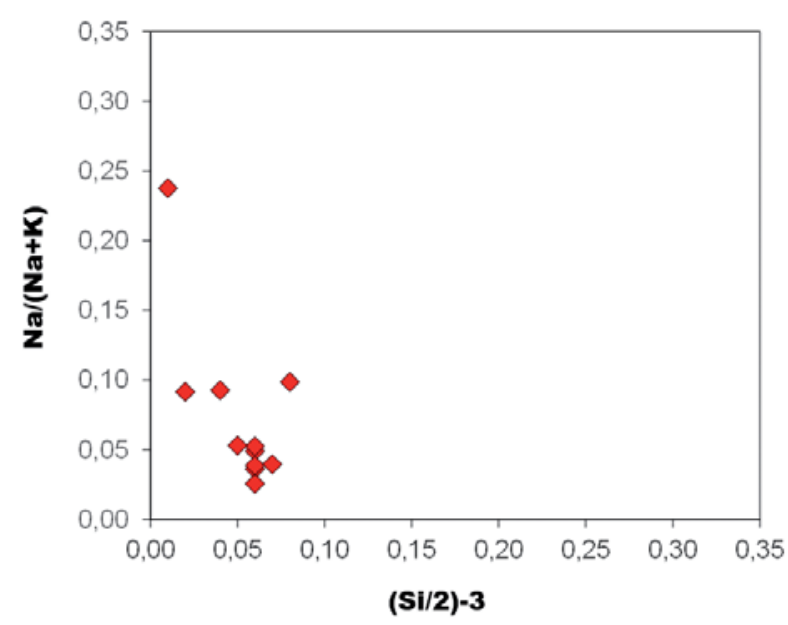

FIGURA 12. Composición química de la moscovita en la paragénesis moscovita + biotita + feldespato alcalino + cuarzo $+\mathrm{H}_{2} \mathrm{O}$ de la Formación Filitas y Esquistos de Busbanzá expresada en el diagrama $\mathrm{Na} /(\mathrm{Na}+\mathrm{K})$ vs. ( $\mathrm{Si} / 2)-3$.

\section{Feldespato}

La composición mineral representativa del feldespato se presenta en la TABLA 3. El porcentaje de anortita en el feldespato varía desde 0.00-2.20 (feldespato alcalino) hasta 2.00-30.50 (plagioclasa). Por otra parte, los porcentajes de ortoclasa varía desde 88.10-97.50 (feldepsato alcalino) hasta 0.90-6.00 (plagioclasa).

\section{Andalucita}

La composición mineral representativa de la andalucita se presenta en la TABLA 4. El contenido de Si varía de $0.970-0.999$, mientras que el contenido de Al varía de 1.975-2.008. La relación Si/Al varía de 0.49-0.50. El contenido de $\mathrm{Fe}^{3+}$ está en el rango 0.010-0.042, con pequeñas cantidades de $\mathrm{Mn}$ y Na hasta de 0.001 .

TABLA 4. Composición mineral representativa de la andalucita en la Formación Filitas y Esquistos de Busbanzá.

\begin{tabular}{|c|c|c|c|c|c|c|c|c|c|c|c|}
\hline \multicolumn{12}{|l|}{ Lithology } \\
\hline $\begin{array}{l}\text { Sample } \\
\text { No. }\end{array}$ & OG029CP & OG029CP & OG029CP & OG029CP & OG029CP & OG033ACP & OG033ACP & OG033ACP & JP203P & JP203P & JP203P \\
\hline $\begin{array}{l}\text { Analysis } \\
\text { No. }\end{array}$ & nucleo & nucleo & nucleo & nucleo & nucleo & nucleo & nucleo & nucleo & nucleo & borde & borde \\
\hline \multicolumn{12}{|l|}{ Weight \% } \\
\hline $\mathrm{SiO}_{2}$ & 37.32 & 36.13 & 36.24 & 36.24 & 36.56 & 36.42 & 36.61 & 36.44 & 35.95 & 35.43 & 35.67 \\
\hline $\mathrm{Al}_{2} \mathrm{O}_{3}$ & 63.14 & 62.35 & 62.14 & 61.86 & 61.98 & 61.68 & 61.53 & 61.71 & 61.43 & 61.92 & 62.04 \\
\hline $\mathrm{Fe}_{2} \mathrm{O}_{3}$ & 0.50 & 0.47 & 0.61 & 0.61 & 0.50 & 1.23 & 1.37 & 1.39 & 2.03 & 1.94 & 1.89 \\
\hline MnO & 0.00 & 0.01 & 0.02 & 0.00 & 0.01 & 0.01 & 0.02 & 0.00 & 0.00 & 0.00 & 0.02 \\
\hline $\mathrm{Na}_{2} \mathrm{O}$ & 0.00 & 0.00 & 0.02 & 0.00 & 0.00 & 0.01 & 0.01 & 0.00 & 0.00 & 0.01 & 0.01 \\
\hline Total & 100.96 & 98.96 & 99.02 & 98.71 & 99.05 & 99.36 & 99.54 & 99.54 & 99.42 & 99.29 & 99.61 \\
\hline \multicolumn{12}{|c|}{ Cation numbers (based on 5 O) } \\
\hline Si & 0.999 & 0.987 & 0.990 & 0.993 & 0.998 & 0.994 & 0.997 & 0.993 & 0.983 & 0.970 & 0.974 \\
\hline Al & 1.992 & 2.008 & 2.000 & 1.997 & 1.993 & 1.983 & 1.975 & 1.981 & 1.980 & 1.999 & 1.996 \\
\hline $\mathbf{F e}^{3+}$ & 0.010 & 0.010 & 0.012 & 0.013 & 0.010 & 0.025 & 0.028 & 0.029 & 0.042 & 0.040 & 0.039 \\
\hline Mn & 0.000 & 0.000 & 0.000 & 0.000 & 0.000 & 0.000 & 0.001 & 0.000 & 0.000 & 0.000 & 0.000 \\
\hline $\mathrm{Na}$ & 0.000 & 0.000 & 0.001 & 0.000 & 0.000 & 0.001 & 0.000 & 0.000 & 0.000 & 0.000 & 0.000 \\
\hline Suma cat. & 3.000 & 3.005 & 3.004 & 3.003 & 3.001 & 3.003 & 3.001 & 3.002 & 3.006 & 3.010 & 3.009 \\
\hline $\mathbf{S i} / \mathbf{A l}$ & 0.50 & 0.49 & 0.50 & 0.50 & 0.50 & 0.50 & 0.50 & 0.50 & 0.50 & 0.49 & 0.49 \\
\hline
\end{tabular}

\section{Óxidos}

La composición mineral representativa de los óxidos se presenta en la TABLA 5. El contenido de $\mathrm{Fe}^{3+}$ está en el rango 0.000-0.132 en la ilmenita y 1.449-1.988 en la magnetita, mientras que el contenido de $\mathrm{Fe}^{2+}$ está en el rango 0.846-0.963 en la ilmenita y 1.000-1.247 en la magnetita, con pequeñas cantidades de $\mathrm{Mn}$ y $\mathrm{Na}$ hasta de 0.001 . Ambos contienen trazas de $\mathrm{Nb}$, aunque mayores en la ilmenita (0.001-0.002). La magnetita presenta además pequeñas cantidades (hasta 0.001 ) de Ni y Zn. 
TABLA 5. Composición mineral representativa de los óxidos en la Formación Filitas y Esquistos de Busbanzá.

\begin{tabular}{|c|c|c|c|c|c|c|c|c|}
\hline \multicolumn{9}{|l|}{ Lithology } \\
\hline Sample No. & \multicolumn{5}{|c|}{ OG029CP-P8 OG029CP-P9 OG033-P6 JP203P-P8 } & JP203P & \multicolumn{2}{|l|}{ OG040P } \\
\hline Analysis No. & & & & & & \multicolumn{3}{|c|}{ cerca a And-Bt } \\
\hline \multicolumn{9}{|l|}{ Weight \% } \\
\hline $\mathrm{SiO}_{2}$ & 0.02 & 0.09 & 0.05 & 0.06 & 0.22 & 0.06 & 0.08 & 0.01 \\
\hline $\mathrm{TiO}_{2}$ & 51.06 & 49.50 & 47.35 & 48.61 & 0.11 & 0.22 & 0.00 & 9.48 \\
\hline $\mathrm{Al}_{2} \mathrm{O}_{3}$ & 0.02 & 0.02 & 0.00 & 0.04 & 0.17 & 0.01 & 0.09 & 0.11 \\
\hline $\mathrm{Cr}_{2} \mathrm{O}_{3}$ & 0.02 & 0.04 & 0.00 & 0.03 & 0.10 & 0.04 & 0.05 & 0.08 \\
\hline $\mathrm{Fe}_{2} \mathrm{O}_{3}$ & 0.00 & 4.52 & 6.33 & 6.89 & 68.77 & 68.32 & 66.08 & 50.68 \\
\hline $\mathrm{FeO}$ & 44.25 & 43.63 & 38.56 & 42.44 & 31.75 & 31.27 & 29.92 & 39.22 \\
\hline MnO & 1.47 & 1.04 & 4.02 & 1.35 & 0.00 & 0.03 & 0.03 & 0.54 \\
\hline MgO & 0.05 & 0.02 & 0.02 & 0.08 & 0.01 & 0.00 & 0.02 & 0.12 \\
\hline $\mathrm{CaO}$ & 0.02 & 0.00 & 0.05 & 0.00 & 0.00 & 0.00 & 0.00 & 0.01 \\
\hline $\mathrm{NiO}$ & 0.00 & 0.00 & 0.00 & 0.00 & 0.02 & 0.00 & 0.03 & 0.02 \\
\hline $\mathrm{ZnO}$ & 0.00 & 0.00 & 0.00 & 0.00 & 0.05 & 0.03 & 0.00 & 0.00 \\
\hline $\mathrm{Nb}_{2} \mathrm{O}_{5}$ & 0.14 & 0.11 & 0.09 & 0.17 & 0.00 & 0.02 & 0.00 & 0.02 \\
\hline Total & 97.06 & 98.50 & 95.84 & 98.98 & 101.20 & 100.00 & 96.30 & 100.29 \\
\hline \multicolumn{9}{|c|}{ Cation Numbers (based on 3-4 O) } \\
\hline Si & 0.001 & 0.002 & 0.001 & 0.001 & 0.008 & 0.002 & 0.003 & 0.000 \\
\hline Ti & 0.999 & 0.952 & 0.935 & 0.929 & 0.003 & 0.006 & 0.000 & 0.271 \\
\hline Al & 0.001 & 0.001 & 0.000 & 0.001 & 0.008 & 0.000 & 0.004 & 0.005 \\
\hline $\mathrm{Cr}$ & 0.000 & 0.001 & 0.000 & 0.001 & 0.003 & 0.001 & 0.002 & 0.002 \\
\hline $\mathbf{F e}^{3+}$ & 0.000 & 0.087 & 0.125 & 0.132 & 1.966 & 1.980 & 1.988 & 1.449 \\
\hline $\mathrm{Fe}^{2+}$ & 0.963 & 0.933 & 0.846 & 0.902 & 1.009 & 1.007 & 1.000 & 1.247 \\
\hline Mn & 0.032 & 0.023 & 0.089 & 0.029 & 0.000 & 0.001 & 0.001 & 0.017 \\
\hline Mg & 0.002 & 0.001 & 0.001 & 0.003 & 0.000 & 0.000 & 0.001 & 0.007 \\
\hline $\mathrm{Ca}$ & 0.001 & 0.000 & 0.001 & 0.000 & 0.000 & 0.000 & 0.000 & 0.000 \\
\hline $\mathbf{N i}$ & 0.000 & 0.000 & 0.000 & 0.000 & 0.001 & 0.000 & 0.001 & 0.001 \\
\hline $\mathbf{Z n}$ & 0.000 & 0.000 & 0.000 & 0.000 & 0.001 & 0.001 & 0.000 & 0.000 \\
\hline $\mathbf{N b}$ & 0.002 & 0.001 & 0.001 & 0.002 & 0.000 & 0.000 & 0.000 & 0.000 \\
\hline Suma cat. & 2.000 & 2.000 & 2.000 & 2.000 & 3.000 & 3.000 & 3.000 & 3.000 \\
\hline Suma $O$ & 3.003 & 3.000 & 3.000 & 3.000 & 4.000 & 4.000 & 4.000 & 4.000 \\
\hline
\end{tabular}

\section{GEOTERMOBAROMETRÍA}

La termobarometría convencional requiere la suposición de que todos los minerales de una roca están totalmente en equilibrio químico entre sí (Spear, 1993). En el presente estudio, aunque se determino la química mineral de las principales fases presentes en la Formación Filitas y Esquistos de Busbanzá, la selección de geotermobarómetros fue complicada, en primer lugar debido a la ausencia de granate y en segundo lugar debido a las características de las diferentes calibraciones disponibles y los rangos de composición de los minerales analizados. Sin embargo, se seleccionaron varios geotermómetros, los cuales incluyen las calibraciones de biotita-moscovita de Hoisch (1991), 
la de plagioclasa-moscovita de Green and Usdansky (1986), el de feldespato ternario de Green and Usdansky (1986) y de Fuhrman and Lindsley (1988), el de dos feldespatos de Stormer (1975), Stormer and Whitney (1985), Powell and Powell (1977), Perchuk et al. (1989), y el de Pl-Ms-Als-Wt de Cheney and Guidotti (1979). Las temperaturas obtenidas producen valores de $540^{\circ} \mathrm{C}$ (Hoisch, 1991), $629^{\circ} \mathrm{C}$ (Green and Usdansky, 1986), 315-545 ${ }^{\circ} \mathrm{C}$ (Green and Usdansky, 1986), 317-895 ${ }^{\circ} \mathrm{C}$ (Fuhrman and Lindsley, 1988), $368^{\circ} \mathrm{C}$ (Stormer, 1975), $416^{\circ} \mathrm{C}$ (Stormer and Whitney, 1985), $368^{\circ} \mathrm{C}$ (Powell and Powell, 1977), $333^{\circ} \mathrm{C}$ (Perchuk et al., 1989), y $607^{\circ} \mathrm{C}$ (Cheney and Guidotti, 1979). El geobarómetro Si-en-fengita (Massonne and Schreyer, 1987) fue aplicado en rocas metapelíticas con la paragénesis cuarzo + muscovita + biotita + plagioclasa. Este es calibrado para rocas que contienen feldespato alcalino, cuarzo y biotita en el sistema $\mathrm{K}_{2} \mathrm{O}-\mathrm{MgO}-\mathrm{Al}_{2} \mathrm{O}_{3}-\mathrm{SiO}_{2}-\mathrm{H}_{2} \mathrm{O}$ (KMASH), a partir del contenido de Si por fórmula unidad (p.f.u.) en la mica blanca (moscovita), el cual tiene una relación casi lineal con la presión de formación, tal como se ilustra en la FIGURA 13 en la que se plotea Si (p.f.u.) vs. Al (p.f.u.), teniendo en cuenta que el exceso de $\mathrm{Si}$ se substituye por $\mathrm{Al}^{\mathrm{IV}}$ en la posición tetrahédrica de la estructura de la moscovita, lo cual es expresado por su naturaleza lineal. Por lo tanto, un aumento en $\mathrm{Si}$ en la moscovita corresponderá a una disminución de Al, lo cual es la base para el barómeto de Si-en-fengita, con mayores contenidos de $\mathrm{Si}$ indicando mayores presiones y viceversa.

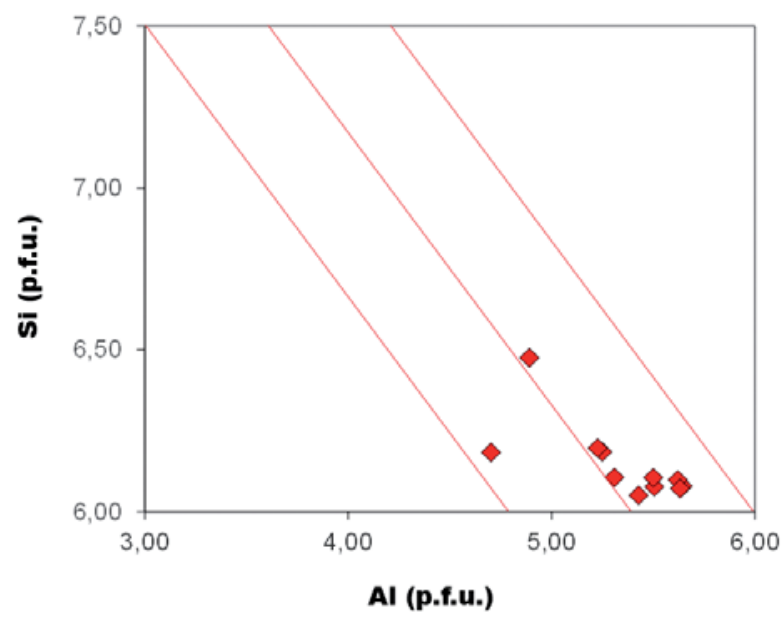

FIGURA 13. Diagrama de Si (p.f.u.) vs. Al (p.f.u.) en la paragénesis moscovita + biotita + feldespato alcalino + cuarzo $+\mathrm{H}_{2} \mathrm{O}$ de la Formación Filitas y Esquistos de Busbanzá. Las líneas a $45^{\circ}$ corresponden a la unión ideal moscovita-Alceladonita, reflejando solo la substitución tschermak (Evans and Patrick, 1987).
A partir del contenido de Si de 6.080 p.f.u. (isopletas de Si de la moscovita en la paragénesis moscovita + biotita + feldespato alcalino + cuarzo $+\mathrm{H}_{2} \mathrm{O}$ ) y un rango de temperatura de $540-629^{\circ} \mathrm{C}$ se determinaron los siguientes rangos de presión (FIGURA 14): entre 0.25 kbar (límite inferior) y 2.1-2.2 kbar (límite superior) apartir de la calibración de Velde (1967), y entre 1.85 kbar (límite inferior) y 2.7-2.8 kbar (límite superior) apartir de la calibración de Massonne and Schreyer (1987). El contenido de Si en la moscovita (6.051-6.475 p.f.u.) es similar al reportado por Evans and Guidotti (1966) en rocas que han sufrido metamorfismo typo Buchan de alto grado.

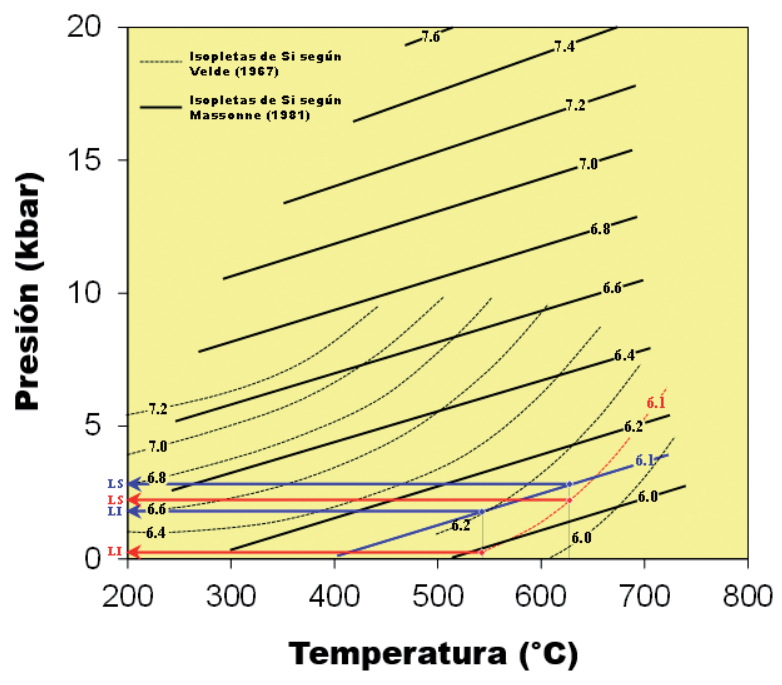

FIGURA 14. Isopletas de Si de la moscovita en la paragénesis moscovita + biotita + feldespato alcalino + cuarzo $+\mathrm{H}_{2} \mathrm{O}$ de acuerdo con Velde (1967) y Massonne and Schreyer (1987), cuyos límites superior e inferior de presión del presente estudio son ilustrados con flechas rojas y azules, respectivamente. LS, límite superior; LI, límite inferior.

\section{DISCUSIÓN}

A pesar de la escaza aparición de minerales índice de metamorfismo, en el presente trabajo proponemos una hipótesis sobre la evolución tectono-metamófica y termal de las rocas metapelíticas del Macizo de Floresta, la cual siguió una trayectoria de PT en sentido horario (FIGURA 15), en condiciones de metamorfismo orogénico regional de presión baja y temperatura baja a intermedia y probablemente hasta alta (?), lo cual es característico de la mayoría de cinturones orogénicos. Esta trayectoria revela como a través del aumento de las condiciones metamórficas, entre las fases 1 y 2 los protolitos de las rocas metamórfica de este macizo fueron enterrados paulatinamente, lo cual 
fue acompañado de un acortamiento y engrosamiento cortical acompañado de al menos dos etapas de deformación $\left(\mathrm{D}_{1} \mathrm{y} \mathrm{D}_{2}\right)$, que producen, respectivamente, un clivaje de pizarrosidad $\left(\mathrm{S}_{1}\right)$ y un clivaje de crenulación $\left(\mathrm{S}_{2}\right)$, hasta alcanzar su máxima profundidad (pico bárico). El resultado de este polimetamorfismo es evidente en las rocas metapelíticas, en donde se desarrollaron filitas y esquistos de grano muy fino a fino, con paragénesis moscovita \pm clorita \pm magnetita + cuarzo, perteneciente a la facies esquistos verdes, con el desarrollo de las zonas de la clorita y la biotita y posiblemente del granate (?). A partir de este punto, el transporte tectónico, las condiciones de presión debieron descender, acompañado de un aumento paulatino de la temperatura hasta alcanzar su pico térmico (3).

Durante esta fase, probablemente se desarrollaron gneises con paragénesis biotita + sillimanita (xenolitos), pertenecientes a la facies de la hornfelsa piróxeno (600$650{ }^{\circ} \mathrm{C}$ ). Sobreimpuesto al metamorfismo regional se presento el emplazamiento de cuerpos intrusivos durante el Ordovícico (4), lo cual se manifiesta en el desarrollo de esquistos con porfiroblastos de andalucita de hasta $5 \mathrm{~mm}$ de diámetro y corneanas con porfidoblastos de andalucita + ortoclasa, pérdida de la foliación con aumento de los tamaños de grano (medio a grueso), los cuales presentan paragénesis moscovita + biotita + andalucita + ortoclasa \pm ilmenita (5), indicando facies de la hornfelsa piróxeno (600$650{ }^{\circ} \mathrm{C}$ ), en donde la andalucita y ortoclasa pueden marcar una reacción de desvolatilización, de baja $\mathrm{P} / \mathrm{T}$, en las aureolas de contacto de las intrusiones graníticas (Stock de Otengá). La ocurrencia de óxidos esta evidenciada en la presencia de magnetita en esquistos, en condiciones de bajo grado de metamorfismo regional, y de ilmenita en corneanas formadas durante el metamorfismo de contacto de alto grado. La andalucita siempre está asociada a la biotita. Los porfiroblastos de andalucita, generalmente presentan textura poiquiloblástica con inclusiones de biotita, la cual hace parte también de la matriz, lo cual indica que estarían relacionadas con el proceso de cristalización del hospedador. No se pudieron definir y/o cartografiar aureolas de metamorfismo de contacto, anque rocas de metamorfismo de contacto de alto grado (corneanas) se identificaron al este y oeste en contacto con el Stock de Otengá, así como en el Cerro Cruz de Piedra. Las intrusiones graníticas aparecen como apófisis que afectan localmente las rocas metamórficas de la Formación Filitas y Esquistos de Busbanzá, lo que permite inferir que las franjas este y oeste del Stock de Otengá constituyen un solo cuerpo intrusivo que se encuentra a poca profundidad. Los autores sugieren que las rocas encajantes adyacentes a este intrusivo pudieron haberse formado a una temperatura de aproximadamente $625{ }^{\circ} \mathrm{C}$ y una presión menor a 3 kbar, con base en la ocurrencia de hornfelsas. El Stock de Otengá probablemente se emplazo en un ambiente dúctil (metamorfismo de grado medio a alto) a una temperatura de aproximadamente $700^{\circ} \mathrm{C}$, sin desarrollo de una aureola de contacto y foliación interna (post-tectónico). Según Kornprobst (1994), la temperatura en cualquier punto del sistema intrusivoroca encajante depende de parámetros, tales como dimensión y temperatura inicial de la intrusión, temperatura inicial de la roca encajante, distancia al centro de la intrusión, conductividad térmica de las rocas y tiempo transcurrido desde el emplazamiento del cuerpo intrusivo. Procesos de anatexis pudieron haber acompañado el desarrollo de isogradas de alto grado (zona de la sillimanita), mientras que la fusión parcial de estas rocas metamórficas pudo ocurrir a temperaturas de aproximadamente $650^{\circ} \mathrm{C}$, en presencia de agua (trayectoria en color verde, FIGURA 15).

Algunos autores relacionan la presencia de granates en esquistos (Jiménez, 2000) y de migmatitas (Sotelo, 1997), los cuales no se observaron en el presente estudio, y que de acuerdo a lo observado en el área a partir del levantamiento estratigráfico, de los análisis petrográficos y de la química mineral no se ajusta al modelo propuesto aquí. Los resultados geotermobarométricos obtenidos apartir de las calibraciones utilizadas revelaron valores de presión $(0.25-2.80 \mathrm{kbar})$ y temperatura $\left(540-629{ }^{\circ} \mathrm{C}\right)$ consistentes entre sí con el desarrollo de una paragénesis moscovita + biotita + feldespato alcalino + cuarzo $+\mathrm{H}_{2} \mathrm{O}$. Las condiciones calculadas corresponden a un metamorfismo de contacto sobreimpuesto al metamorfismo regional. Estos datos indican regionalmente para el Macizo de Floresta la ocurrencia de un evento termal asociado al emplazamiento de cuerpos intrusivos de poca profundidad (Stock de Otengá). 

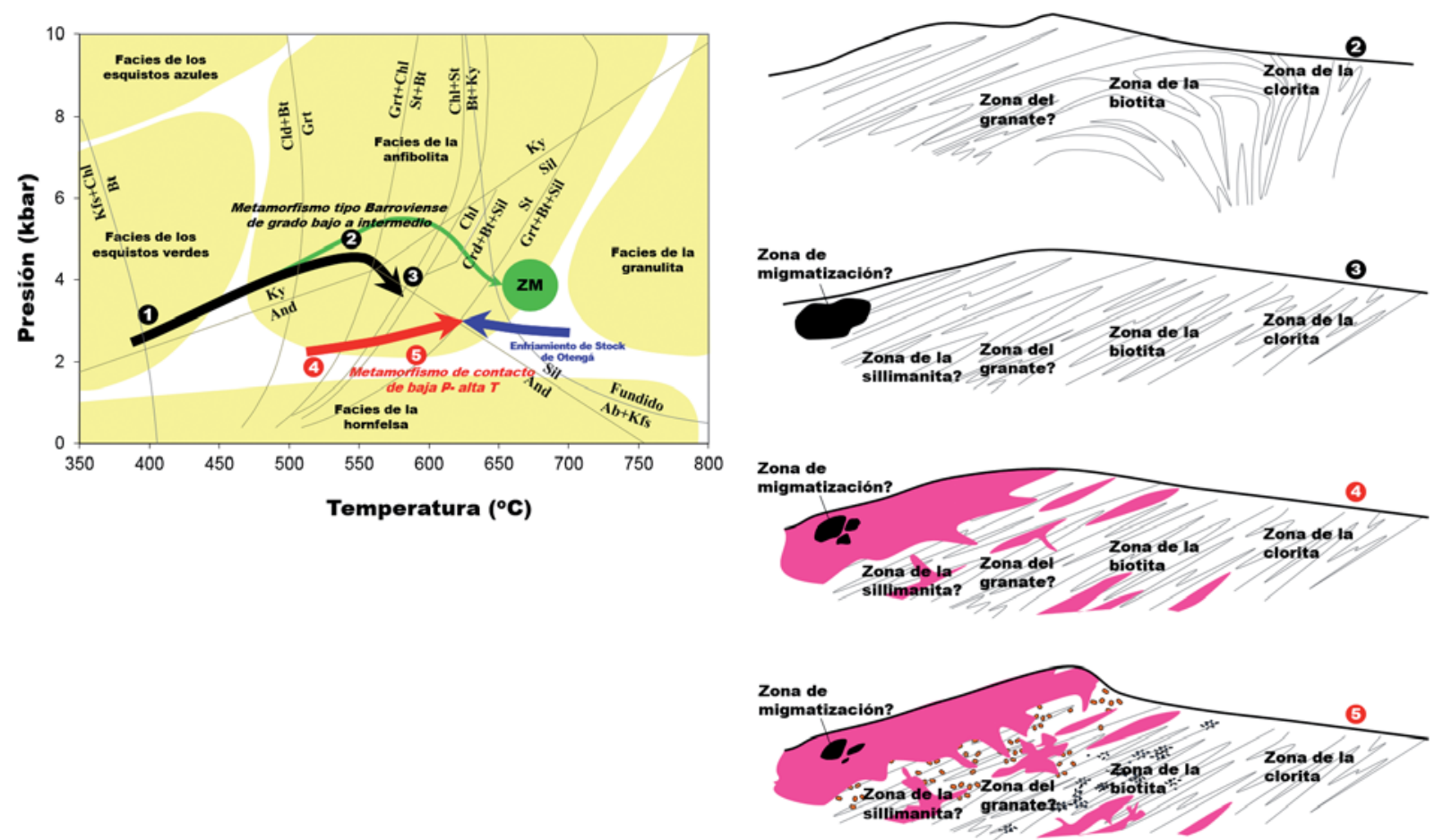

FIGURA 15. Diagrama de PT mostrando las condiciones estimadas para la evolución tectono-metamórfica y termal de la Formación Filitas y Esquistos de Busbanzá. Red petrogenética en el sistema $\mathrm{K}_{2} \mathrm{O}-\mathrm{FeO}-\mathrm{MgO}-\mathrm{Al}_{2} \mathrm{O}_{3}-\mathrm{SiO}_{2}-\mathrm{H}_{2} \mathrm{O}(\mathrm{KFMASH})$ para rocas pelíticas (modificada después de Spear and Cheney, 1989; Yardley, 1989; Bucher and Frey, 1994). Punto tripe del $\mathrm{Al}_{2} \mathrm{SiO}_{5}$ según Holdaway (1971). Las áreas en amarillo representan las facies metamórficas. Trayectoria en sentido horario (flecha negra) seguida por las rocas metamórficas de la Formación Filitas y Esquistos de Busbanzá. La flecha verde indica la trayectoria propuesta con base en las observaciones realizadas por Sotelo (1997). El círculo verde indica el campo de formación de la zona de migmtización (ZM). La flecha roja indica la trayectoria correspondiente al metamorfismo de contacto de baja P- alta T. La flecha azul indica el hipotético enfriameento del Stock de Otengá.

\section{CONCLUSIONES}

En el Macizo de Floresta, la Formación Filitas y Esquistos de Busbanzá, constituyen el núcleo más antiguo aflorante en el área, de edad pre-ordovícica, de acuerdo a la datación del Stock granítico de Chuscales (471 $\pm 22 \mathrm{Ma})$, que intruye a estas rocas metamórficas. El grado de metamorfismo regional que sufrieron las rocas metapelíticas, limitó la aparición de nuevos minerales, y su paragénesis cuarzo + moscovita \pm clorita \pm magnetita. Localmente, ocurren gneises (paragneises), los cuales se caracterizan por su estructura bandeada. Estos, al igual que las corneanas con las cuales están asociados, presentan una paragénesis moscovita + biotita + andalucita \pm ortoclasa \pm ilmenita, son el resultado de un metamorfismo de contacto facies hornfelsa piróxeno
(600-650 $\mathrm{C}$ ) asociado al emplazamiento de cuerpos intrusivos de composición esencialmente granítica. La Formación Filitas y Esquistos de Busbanzá, conforman una franja alargada SW-NE limitada al este y al oeste por rocas graníticas del Stock de Otengá, el cual de acuerdo a éste estudio se encuentra a poca profundidad bajo la secuencia metapelítica de esta unidad geológica, ya que los levantamientos estratigráficos realizados revelaron la presencia no solo de corneanas y apofísis de este stock sino también de xenolitos (corneanas de sillimanita+biotita) dentro de apófisis ígneas. En el presente estudio se descarta a partir de datos de química mineral la presencia de cordieritas reportadas en estudios previos, las cuales corresponden a ortoclasas, cambiando de esta manera la paragénesis mineral y las condiciones de PT de metamorfismo. Las rocas metapelíticas de 
esta unidad geológica evidencian un polimetamorfismo como resultado de al menos dos etapas de deformación $\left(\mathrm{D}_{1}\right.$ y $\left.\mathrm{D}_{2}\right)$, que producen, respectivamente, un clivaje de pizarrosidad $\left(\mathrm{S}_{1}\right)$ y un clivaje de crenulación $\left(\mathrm{S}_{2}\right)$, con paragénesis moscovita \pm clorita \pm magnetita + cuarzo, perteneciente a la facies esquistos verdes, con el desarrollo de las zonas de la clorita y la biotita y posiblemente del granate (?). La ocurrencia de neises con paragénesis biotita + sillimanita (xenolitos) define el aumento de las condiciones de metamorfismo hasta la facies de la hornfelsa piróxeno $\left(600-650{ }^{\circ} \mathrm{C}\right)$. La presencia de esquistos con porfiroblastos de andalucita y corneanas con porfidoblastos de andalucita + ortoclasa, con paragénesis moscovita + biotita + andalucita + ortoclasa \pm ilmenita (facies de la hornfelsa piróxeno, $600-650^{\circ} \mathrm{C}$ ), revelan la ocurrencia de un evento térmico (asociado al emplazamiento de cuerpos intrusivos durante el Ordovícico) sobreimpuesto al metamorfismo regional, aunque sin desarrollo de aureolas de contacto. Uno de los principales aportes de éste estudio es el modelo hipotético propuesto para explicar la evolución tectono-metamórfica y termal de la Formación Filitas y Esquistos de Busbanzá a partir de datos de petrografía, química mineral y geotermobarometría en conjunto con observaciones de campo.

\section{AGRADECIMIENTOS}

Queremos agradecer a al Servicio Geológico Colombiano, por apoyar la realización de la Cartografía Geológica y Prospección Geoquímica del Macizo de Floresta, a COLCIENCIAS por el intercambio de investigadores con la Universidad de Sao PauloUSP (Brasil). A Silvio Farias Vlach por permitirnos realizar los ensayos de química mineral en la USP. A los grupos de investigación en Ingeniería Geológica de la Universidad Pedagógica y Tecnológica de Colombia, en Geología Básica y Aplicada de la Universidad Industrial de Santander, y en Geofísica y Geología de la Universidad de Pamplona, por las discusiones en torno al presente trabajo.

\section{REFERENCIAS}

Botero, J. 1950. Reconocimiento geológico del área comprendida entre los municipios de Belén, Cerinza, Floresta, Nobsa y Santa Rosa de Viterbo, Depto. de Boyacá. INGEOMINAS, Informe 534; CEGOC, 8: 244-311.

Bucher, K., and Frey, M. 1994. Petrogenesis of metamorphic rocks. Complete revision of Winkler's textbook. $6^{\text {th }}$ edition. Springer-Verlag. Berlin, $318 \mathrm{p}$.
Castellanos, O.M., Ríos, C.A., and Takasu, A. 2008. A new approach the tectonometamorphic mechanisms associated with P-T paths of the Barrovian type Silgará Formation at the Central Santander Massif, Colombian Andes. Earth Sciences Research Journal, 12(2): 125-155.

Cediel, F. 1969. Geología del Macizo de Floresta. I Congreso Cololombiano de Geología, Bogotá, pp. 17-29.

Cediel, F. 1976. Geología del Macizo de Floresta. Nota explicativa del mapa geológico. INGEOMINAS. Bogotá.

Cheney, J.T., and Guidotti, C.V. 1979. Muscoviteplagioclase equilibria in sillimanite + quartz-bearing metapelites, Puzzle Mountain area, Northwest Maine. American Journal of Science, 279: 411-434.

Cohen, K.M., Finney, S.C., Gibbard, P.L., and Fan, J.X. 2013. The ICS International Chronostratigraphic Chart. Episodes, 36(3): 199-204.

Cooper, M., Adisson, F., Álvarez, R., Coral, M., Graham, R., Hayward, A., Howe, S., Martínez, J., Naar, J., Peñas, R., Pulham, A., and Taborda, A. 1995. Basin development and tectonic history of the Llanos Basin, Eastern Cordillera, and Middle Magdalena Valley, Colombia. AAPG Bulletin, 79(10): 1421-1443.

Evans, B.W., and Guidotti, C.V. 1966. The sillimanitepotash feldspar isograd in Western Maine, U.S.A. Contributions to Mineralogy and Petrology, 12(1): 25-62.

Evans, B.W., and Patrick, B.E. 1987. Phengite-3T in high-pressure metamorphosed granitic orthogneisses, Seward Peninsula, Alaska. Canadian Mineralogist, 25: 141-158.

Fuhrman, M.L., and Lindsley, D.H. 1988. Ternary feldspar modeling and thermometry. American Mineralogist, 73: 201-215.

Green, N.L., and Usdansky, S.I. 1986. Toward a practical plagioclase-muscovite thermometer. American Mineralogist, 71: 1109-1117.

Hoisch, T. 1991. Equilibria within the mineral assemblage quartz + muscovite + biotite + garnet + plagioclase, and implications for the mixing properties of octahedrally-coordinated cations in muscovite and biotite. Contributions to Mineralogy and Petrology, 108(1): 43-54. 
Holdaway, M. 1971. Stability of andalusite and the aluminum silicate phase diagrams. American Journal of Sciences, 271(2), 97-131.

Jiménez, D. 2000. Catálogo de las unidades litoestratigráficas de Colombia, Filitas y Esquistos de Busbanzá. INGEOMINAS.

Kornprobst, J. 1994. Les roches métamorphiques et leur signification géodinamique: Précis de pétrologie. Masson. Paris, 223p.

López, A., y Mesa, J.E. 1997. Estratigrafía y ambientes de depósito de la Formación Girón en el Macizo de Floresta (Boyacá). Tesis grado, Universidad Nacional de Colombia. Bogotá.

Manosalva, S., Mariño, J., y Reyes, I. 2010. Cartografía geológica y prospección geoquímica del Macizo de Floresta. INGEOMINAS. Bogotá.

Massonne, H.J., and Schreyer, W. 1987. Phengite geobarometry based on the limiting assemblage with $\mathrm{K}$-feldspar, phlogopite, and quartz. Contributions to Mineralogy and Petrology, 96(2): 212-224.

Mojica, J., y Villaroel, C. 1984. Contribución al conocimiento de las unidades paleozoicas del área de Floresta (Cordillera Oriental Colombiana, Departamento de Boyacá) y en especial al de la Formación Cuche. Geología Colombiana, 13: 55-80.

Perchuk, L.L., Gerya, T.V., and Nozhkin, A.D. 1989. Petrology and retrograde P-T path in granulites of the Kanskaya formation, Yenisey range, Eastern Siberia. Journal of Metamorphic Geology, 7(6): 599-617.

Powell, M., and Powell, R. 1977. Plagioclase-alkali feldspar geothermometry revisited. Mineralogical Magazine, 41: 253-256.

Reyes, I. 1984. Geología de la región de DuitamaSogamoso-Paz de Río (Departamento de Boyacá). Inédito, UPTC, Sogamoso.

Ríos, C.A., García, C.A., and Takasu, A. 2003. Tectonometamorphic evolution of the Silgará Formation metamorphic rocks in the southwestern Santander Massif, Colombian Andes. Journal of South American Earth Sciences, 16(2): 133-154.

Sotelo, C. I. 1997. Informe de comisión de campo Macizo de Floresta. INGEOMINAS. Informe preliminar, inédito.
Spear, F.S., and Cheney, J. 1989. A petrogenetic grid for pelitic schists in the system $\mathrm{SiO}_{2}-\mathrm{Al}_{2} \mathrm{O}_{3}-\mathrm{FeO}-\mathrm{MgO}-$ $\mathrm{K}_{2} \mathrm{O}-\mathrm{H}_{2} \mathrm{O}$. Contributions to Mineralogy and Petrology, 101(2), 149-164.

Spear, F. 1993. Metamorphic phase equilibria and pressure-temperature-time paths. Monograph Series, Mineralogical Society of America, Washington, DC, 799pp.

Stormer, J.C., Jr. 1975. A practical two-feldspar geothermometer. American Mineralogist, 60: 667-674.

Stormer, J.C., and Whitney, J.A. 1985. Two-feldspar and iron-titanium oxide equilibria in silicic magmas and the depth of origin of large volume ash-flow tuffs. American Mineralogist, 70: 52-64.

Ulloa, C., y Rodríguez, G.I. 1982. Intrusivos ácidos Ordovícicos y post - Devónicos en la Floresta (Boyacá). VI Congreso Cololombiano de Geología, Cali.

Ulloa, C., Guerra, A., y Escobar R. 1998. Geología Plancha 172 - Paz de Río. Escala 1:100.000. INGEOMINAS. Bogotá.

Ulloa, C., Rodríguez, E., y Rodríguez, G. 2003. Geología de la plancha 172 - Paz de Río. Memoria explicativa INGEOMINAS. 105p.

UPTC - INGEOMINAS. 2010. Cartografía geológica y prospección geoquímica del Macizo de Floresta. Convenio 023 UPTC-INGEOMINAS.

Velandia, F. 2005. Interpretación de transcurrencia de las Fallas Soapaga y Boyacá a partir de imágenes LANDSAT TM. Boletín de Geología, 27(44): 81-94.

Velde, B. 1967. $\mathrm{Si}^{+4}$ content of natural phengites. Contributions to Mineralogy and Petrology, 14(3): 250258.

Ward, D., Goldshmith, R., Cruz, J., y Restrepo, H. 1973. Geología de los cuadrángulos H-12 Bucaramanga y H-13 Pamplona, departamento de Santander. Boletín Geológico, INGEOMINAS, 21(1-3):1-132.

Yardley, B. 1989. An Introduction to Metamorphic Petrology. Prentice Hall. Harlow, 248p.

Trabajo recibido: junio 29 de 2016

Trabajo aceptado: noviembre 18 de 2016

Manuscrito publicado en internet: diciembre 05 de 2016 